\title{
LA EDAD DEL BRONCE EN EL INTERIOR PENINSULAR. UNA APROXIMACIÓN AL II MILENIO A.C. EN LAS CUENCAS DE LOS RIOS DUERO Y TAJO ${ }^{1}$
}

\author{
M. ${ }^{a}$ CONCEPCIÓN BLASCO BOSQUED \\ Dep. de Prehistoria y Arqueologia \\ Universidad Autónoma de Madrid
}

\section{Resumen}

Este trabajo ofrece un panorama general de la Edad del Bronce en las cuencas del Duero y Tajo. En él se recoge un elenco de las dataciones obtenidas en contextos claros y se revisan los rasgos culturales más destacables de los sucesivos horizontes, a partir de los datos que ofrecen los asentamtentos, las manifestaciones funerarias y los materiales muebles recuperados en ellos.

\section{Abstract}

In this paper general panorama of the Bronze Age in the Duero and Tajo Valley's is presented. The article provides several dates for different settements, and aiso principal features of successive horizons reviews, analysing establishments funeral rituals and furniture remains finds.

El despegue de los estudios sobre la Edad del Bronce en las cuencas del Duero y Tajo se produce en la década de los 70 . con la proliferación de hallazgos de cerámicas decoradas del Horizonte Cogotas I que, poco a poco, permiten trazar un marco cronológico y cultural de este Horizonte dentro del Bronce Tardio y Final. Todos estos hallaz-

${ }^{1}$ Este trabajo ha sido realizado dentro del Proyecto PB0020-96 Subvencionado por el MEC, Dirección General del Conocimiento dentro del Plan General de Ayuda a la Investigación. 
gos contribuyen a aumentar la, hasta entonces, escasa nómina de yacimientos de la Edad del Bronce meseteño. No obstante, no es hasta muy a finales de los años $70 \mathrm{y}$, sobre todo, durante las dos últimas décadas, cuando comenzamos a tener datos sobre las características de los yacimientos en los que se encuentran estos materiales cerámicos y a precisar, con argumentos más fiables, la posición cronológica que ocupan. Paralelamente, se va definiendo otro horizonte algo anterior, caracterizado por las cerámicas lisas y una serie de rasgos relativamente próximos al mundo argárico. No obstante, la todavía corta trayectoria investigadora en esta área y la escasez de trabajos de campo sobre la Edad del Bronce con resultados publicados no permiten establecer aún un panorama muy definitivo.

Por otra parte, conviene resaltar que, dentro del amplio marco geográfico, el nivel de conocimiento con que contamos es muy desigual según las diferentes regiones. En efecto, mientras que algunas áreas del Duero, como es su cuenca alta (JjMENO, A., y FERNANDEZ MORENO, J. J., 1992), o determinados territorios provinciales (DELIBES, G., 1995 a y 1995b, y DELIBES, G., y ESPARZA, A., 1985), han sido objeto de recientes sintesis que permiten obtener un panorama general, otras zonas permanecen casi inéditas o no cuen$\tan$ con revisiones recientes en las que se hayan incorporado nuevos hallazgos o se hayan reinterpretado antiguos descubrimientos.

La desigual información que poseemos para los diversos territorios que integran el Valle del Duero puede trasladarse también a la cuenca del Tajo donde existen dos áreas bien diferenciadas: la Cuenca Media y el Alto Tajo. La Cuenca Media ha permanecido prácticamente inédita hasta hace una década y apenas se han realizado excavaciones sistemáticas, afortunadamente estas lagunas comienzan a ser subsanadas con prospecciones intensivas y algunas excavaciones puntuales que están arrojando bastante luz (CARROBLES, J.; MUÑNOZ, K., y RODRÍGUEZ, S., 1994) En el Alto Tajo el panorama es algo diferente aunque todavia estemos lejos de contar con un nivel de conocimiento satisfactorio. Concretamente para la provincia de Madrid contamos con una abundante bibliografia que parte de los trabajos de Pérez de Barradas, realizados a comienzos de siglo, los cuales, tras un paréntesis prolongado, han tenido su continuación en las tres últimas décadas, sin embargo la "urgencia" con que se han tenido que llevar a cabo todas las intervenciones han restado profundidad a las investigaciones $\mathrm{y}$, en consecuencia, a la información que se ha podido extraer de ella. En la provincia de Guadalajara recientes síntesis nos permiten tener una idea de los datos que ofrecen diversos trabajos de prospección sistemática (DÍAZ-ANDREU, M.,1994a y 1994b, y BUENO, P., JiMÊNEZ, P. J., y BARROSO, $R, 1995)$; a estas sintesis se suma la información que ha proporcionado el singular yacimiento de La Loma del Lomo de Cogolludo que sirve de paradigma del Bronce Antiguo y Pleno en la zona (VALIENTE, J., 1984 y 1992).

La diferente intensidad de información puede trasladarse también a los distintos horizontes cronológicos que se desarrollan a lo largo del il milenio, pues los trabajos llevados a cabo no permiten tener un conocimiento regular, ya que mientras los estudios sobre el campaniforme cuentan con una tradición bibliográfica (CASTiLLO, A. del, 1928; DELIBES, G., 1977: HARRISON, R., 1977. y BLASCO, C., ed.1994) que ha permitido documen- 
tar una gran proliferación de hallazgos, aunque a veces de muy poca entidad y el horizonte Cogotas I ha generado durante las tres últimas décadas una cantidad ingente de aportaciones, de difícil sistematización, que ha hecho posible su definitiva ubicacion dentro de un amplio espacio temporal que cubre la segunda mitad del segundo milenio abarcando desde el Bronce Pleno al Bronce Final, la etapa intermedia, caracterizada por la presencia de cerámicas sin decorar, centrada en los siglos XVII y XVI a.C., ha merecido mucha menos atención, por lo que, "en cierto modo justificaria la calificación de "oscura" con la que algún autor denomina a esta fase" (FERNÁNDEZ MANZANO, j., 1985: 59) y a la que también se la ha denominado "la etapa anterior" en contraposición a "la etapa de apogeo" con la que se ha definido al Horizonte Cogotas I (FERNÁNDEZ MANZANO. J., 1985: 58 y 66$)$.

Los avances de la investigación permiten vislumbrar ya algunos de los parámetros en los que se desenvuelve la Edad del Bronce en estas dos grandes cuencas fluviales, sus paralelos y relaciones con otros círculos culturales del bronce peninsular, así como su papel en las relaciones e intercambios entre las diferentes áreas y han contribuido también a trazar un denso mapa de yacimientos encuadrados en la Edad del Bronce y a obtener un listado de dataciones radiocarbónicas correspondientes al II milenio. No obstante quedan todavía algunos pasos por recorrer para conocer bien, tanto las caracteristicas y singularidades de los diversos círculos, como su origen y desarrollo, además del mecanismo de sus relaciones.

\section{LA CUESTION DE LA CRONOLOGIA CAMPANIFORME Y SU SINCRONIA CON EL BRONCE ANTIGUO}

En el estado actual de la investigación, uno de los principales escolios sigue siendo la elaboración de una secuencia cronocultural que sirva de marco general ya que no existen bases concretas y fiables que garanticen el surgimiento sincrónico de la Edad del Bronce en toda esta amplia área o la existencia de amplios circulos que evolucionen de manera similar en todo el territorio objeto de estudio. es más. algunos de los datos disponibles hacen sospechar la convivencia de grupos con tradiciones diferentes dentro del mismo marco temporal como ocurre al final del Horizonte Campaniforme y al inicio de la Edad del Bronce, según se desprende de las pocas dataciones que tenemos para esos horizontes. Las relativas al Horizonte campaniforme son las siguientes: 
TABLA 1

\begin{tabular}{|c|c|c|c|c|c|c|}
\hline Yacimiento & Laboratorio & $b_{p}$ & a.c. & $\begin{array}{l}\text { Cat. } \\
\text { ane }\end{array}$ & \pm ane & Bibllografia \\
\hline \multicolumn{7}{|l|}{ CUENCA DEL DUERO } \\
\hline Fuente Olmedo & CSIC- 483 & 3660 & $1710^{2}$ & 2053 & 50 & Castro. Lull. y Micó, 1996 \\
\hline Fuente Olmedo & 1-10.768 & $3255^{*}$ & 1305 & & 90 & Martin Valts. Delibes 1989 \\
\hline Aldeagordillo & GrN-19167 & 3685 & $\mathbf{1 7 3 5}$ & 2086 & 25 & Castro, Lull, y Micó, 1996 \\
\hline Aldeagordillo & GrN-19168 & 4115 & 2165 & & 20 & Fabián, F.j.. 1995 \\
\hline \multicolumn{7}{|l|}{ CUENCA DEL TAJO } \\
\hline E! Ventorro (campanif) & $\mathrm{I}-1248$ & $4800^{*}$ & 2850 & & 130 & Prtego y Quero. 1992 \\
\hline El Ventorro (precamp) & I-11923 & 4290 & 2340 & & 250 & Priego y Quero, 1992 \\
\hline El Ventorro (precamp) & I-12100 & 3880 & 1930 & 2365 & 90 & Castro, Lull, y Mico, 1996 \\
\hline Cuesta de la Mora. Ciempozuelos. & UAM. TL & 3694 & 1697 & & 285 & Blasco, Baena y Liesau, 1997 \\
\hline
\end{tabular}

A la vista de la presente tabla se deduce que son muy pocas las dataciones disponibles para el campaniforme de estas cuencas, sobre todo si tenemos en cuenta la cantidad de yacimientos conocidos y, además, son poco aprovechables ya que no contamos con series largas que las hagan más fiables por lo que todos estos datos que presentamos deben de tomarse con la prudencia que requiere la obtención de una o, a lo sumo, dos dataciones. No obstante sí queremos destacar un dato: las tres dataciones que corresponden a contextos claros (en negrita) bajan la cronología del estilo Ciempozuelos hasta los siglos XVII-XVIII antes de nuestra era, en fechas no calibradas, y llegan al límite del III-II milenios en los valores calibrados, un dato que, de confirmarse, deja prácticamente sin espacio cronológico exclusivo a un horizonte de Bronce Antiguo-Medio con cerámicas lisas como encontramos en la tercera gran cuenca de la Meseta: la del Guadiana.

De todas formas la problemática no es sólo de nuestra área de estudio pues la situación se repite en otras regiones peninsulares, ya que estos valores se encuentran relativamente próximos a una buena parte de las fechas de $\mathrm{C} 14$ que, hasta el momento, teniamos para niveles con campaniforme. Así, por ejemplo, el nivel con campaniforme de Zambujal proporcionó un valor de $3625 \pm 65$ B.P. (POYATO, M. ${ }^{a}$ C.. 1984-85: 95); Los Dornajos, con cerámicas consideradas epigonales, ofreció unas fechas de 3550 y 3520 B.P. \pm 50 (GalÁ, C. y FernándeZ-VEGA, A.,1983) y la fase I de La Pijotilla (Precampaniforme) aporto un 3960 B.P. \pm 70 (HURTADO, V., 1987: 43). Unos valores no muy alejados han proporcionados las dos dataciones conocidas para yacimientos campaniformes navarros de la región de Las Bardenas Reales: Marijuan y Monte Aguilar, ambos con idéntico valor: 1610 a. C. \pm 100 (SESMA, J., 1993:96).

${ }^{2}$ Las fechas con negritas corresponden a contextos Ciempozuelos claros y las que tienen asterisco han sido invalidadas por presentar dudas. En el listado no se incluyen las correspondientes al nivel ILA de la Cueva de Arevalillo de Cega ya que las cerárnicas campaniformes se asocian a las típicas de Cogotas I. 
Por el contrario, estos valores resultan mucho más bajos que las dataciones deparadas por otros yacimientos de este mismo horizonte, algunos de ellos, como La Atalayuela, con ejemplares cerámicos del "tipo Ciempozuelos", donde se han obtenido tres fechas casi idénticas que hacen bastante fiables los resultados $(4110 \pm 60,4120 \pm 70$ y $4060 \pm 60 \mathrm{bp}$ ). Un caso similar es el de Hoyas del Castillo de Pajaroncillo, cuyo nivel 1 . con cerámicas decoradas, tipo Dornajos, ha sido fechado en un $3940 \pm 60$ (ULREICH, H., NEGRETE, M. ${ }^{a}$ A., y PUCH, E., 1994:131) y por tanto resulta bastante más antiguo que el yacimiento epónimo. También algunos de los yacimientos campaniformes del Valle Medio del Ebro con distintos estilos se han fechado en torno a mediados del tercer milenio a. C., si bien alguno de ellos, como Majaladares, con campaniformes tipos Ciempozuelos, ha ofrecido valores distanciados en ocho centurias (ANDRÉS. M. ${ }^{a}$ T., 1997-75) que prolongan este horizonte entse el 2400 y el 1600 (cal) La distancia, con respecto a las bajas dataciones de muchos de los yacimientos meseteños resulta todavia mayor si aceptamos las fechas de la Cueva de Somaén: $4730 \pm 130$ y $4620 \pm$, que nos llevan hasta el 3535 y 3345 AC en fechas calibradas (CASTRO, P.; Lull, V., y MiCO, R., 1955, listado final), lo que obligaría a prolongar el horizonte durante un milenio.

Seguimos, por tanto, sin poder precisar, con seguridad, la posición del campaniforme meseteño en general, y el estilo Ciempozuelos en particular, para el que se admite una antigüedad que oscila entre la segunda mitad del tercer milenio y el cambio del III al II milenio a.C. pero no estamos en condiciones de poder precisar más y. en consecuencia, tenemos que seguir planteando la posibilidad de su coetaneidad con el horizonte de cerámicas lisas. Llegados a este punto resulta difícil presentar el Horizonte Campaniforme como el final del Calcolítico y no como una manifestación del Bronce Antiguo en la Meseta donde cada vez resulta más difícil aplicar la tradicional periodización tripartita de Bronce Antiguo, Medio y Final y, mucho menos, confirmar que los diferentes estilos y modas decorativas cerámicas sean indicadores de horizontes cronológicos precisos y diacrónicos entre sí.

\section{EL BRONCE ANTIGUO Y PLENO: EL HORIZONTE DE CERÁMICAS LISAS}

Ha sido, hasta hace poco, el horizonte peor conocido, sin embargo, en los últimos años se han producido importantes avances en ambas cuencas y los datos con los que hoy contamos indican que se trata de grupos con una gran personalidad aunque queden un poco "al margen del fenómeno de concentración demográfica y urbanización reconocido en los poblados del sureste (El Argar), de Levante (Bronce valenciano) o [de las regiones más meridionales\} de la submeseta sur (Las Motillas)" (DELIBES, G., 1995, b: 88). Por otra parte, todo parece indicar que, al menos en los primeros momentos de esta fase, existen bastantes elementos comunes con el Horizonte Campaniforme, y, en las etapas avanzadas, se observa una cierta identificación con Protocogotas I. Este hecho parece tener su reflejo en las pocas dataciones obtenidas en yacimientos adscritos al horizonte que nos ocupa ya que parecen solaparse, tanto con las fechas más recientes del Campa- 
niforme como con las más antiguas de Cogotas I. Las dataciones conocidas son las siguientes:

\section{TABLA 2}

\begin{tabular}{|c|c|c|c|c|c|c|}
\hline yactmiento & Laborator io & bp & a.C. & cal ane & \pm ane & Blbllografia \\
\hline \multicolumn{7}{|l|}{ CUENCA DEL DUERO } \\
\hline El Parpantique & & 3730 & 1780 & 2125 & 30 & Castro, Lull y Mico 1996 \\
\hline Los Torojones & & 3520 & 1670 & 1981 & 30 & Castro, Lull y Micó 1996 \\
\hline Santioste & & 3780 & 1830 & 2244 & 80 & Castro, Lull y Micó 1996 \\
\hline Santioste & & 3750 & 1800 & 2182 & 80 & Castro, Lull y Mico 1996 \\
\hline El Tomilar & GrN-17344 & 3780 & 1830 & 2442 & 100 & Castro. Lull y Mico 1996 \\
\hline E! Tonitlar & GrN-17345 & 3830 & 1880 & 2224 & 95 & Castro. Luil y Mico 1996 \\
\hline El Tomillar & GrN. 18875 & 3925 & 1975 & & 40 & Fabián, 1995 \\
\hline \multicolumn{7}{|l|}{ CUENCA DEL TAJO } \\
\hline Loma del Lomo ${ }^{3}$ & I-15329 & 3780 & 1830 & 2255 & 110 & Castro, Lull y Mico 1996 \\
\hline Loma del Lomo & I- 14220 & 3450 & 1500 & & 160 & Castro, Lull y Micó 1996 \\
\hline Loma del Lomo & I-14891 & 3340 & 1390 & 1630 & 100 & Castro. Lull y Mico 1996 \\
\hline Terrazas Manzanares & CSIC 176 & 3050 & 1100 & 1310 & 100 & Castro, Lull y Micó 1996 \\
\hline Terrazas Manzanares & CSIC 182 & 3050 & 1100 & 1310 & 100 & Castro, Lull y Mico 1996 \\
\hline
\end{tabular}

De la presente tabla se desprende que, salvo las fechas de las Terrazas del Manzanares, de contexto dudoso, el resto de los yacimientos se encuentran en un marco cronológico entre el 1900 y el 1400 a.C. que en fechas calibradas se eleva hasta un 2.4401630 a.C.. Este cuadro temporal nos lleva a sincronizar el inicio de la Edad del Bronce en las cuencas del Duero y Tajo con la región Manchega y, en general, con las tierras más meridionales de la Meseta a las que se les había concedido una gran antigüedad (FERNANDEZ-POSSE, M. ${ }^{2}$ D.: GILMAN, A., y MARTín, C., 1996) Por otra parte, si comparamos estas dataciones con las del campaniforme en estas mismas cuencas del Duero y Tajo, observaremos que se produce un claro solapamiento por lo que, a falta de obtener repertorios más amplios que permitan mejor contrastación, habria que aceptar una cierta sincronia entre ambas facies, una posibilidad que parece confirmarse por la similitud entre el enterramiento de Santioste y el ritual funerario campaniforme, no sólo por el modelo de enterramiento, sino también, por el propio ajuar.

${ }^{3}$ En esta tabla hemos onitido las tres fechas más antiguas del poblado de La Loma del Lomo ya que han sido atribuídas por su excavador a una fase de ocupación Calcolitica 
En la Cuenca del Duero, hace ya unos años el Bronce Antiguo se identificó con el Horizonte Parpantique, (JIMENO, A., y FERNÁNDEZ, J. J., 1992: 86) cuyo yacimiento epónimo, situado en la Cuenca alta (Soria), ha proporcionado una datación de 1780 a.C. (Vid tabla 2).Los poblados de nueva fundación se encuentran ubicados sobre cerros, en la transición del páramo a la campiña, dominando extensas zonas y, aunque carecen de fortificaciones, están provisto de una buena defensa natural. En general, presentan una disposición de las viviendas en tomo a un espacio central. Entre ellos está El Parpantique de Balluncar que controla una amplia zona de la vega del Duero. Posee viviendas de planta rectangular, con una superficie alrededor de los $30 \mathrm{~m}^{2}$, divididas en dos ambientes, en el más reducido se encuentran, además del hogar, grandes recipientes de almacenamiento, mientras que el espacio más amplio, posiblemente dedicado a distintas actividades, contiene los molinos y restos de grano (JIMENO, A., y FERNÁNDEZ, J. J., 1992: 88-89) El alto número de recipientes contenedores (silos o grandes cerámicas) se ha interpretado como la existencia de una mayor cantidad de excedentes.

Las zonas mejor prospectadas parecen evidenciar una cierta diversificación en la ocupación del territorio, tanto por su presencia en zonas montañosas y de llanura, como por el tipo de asentamiento: al aire libre y en cueva o por su ubicación en cerro y en bajo. Todo parece indicar que nos encontramos con grupos que tienden a incrementar y diversificar sus recursos, con una cierta intensificación de la actividad agrícola.

En la actualidad son ya muchos los sitios, repartidos por toda la cuenca del Duero, que pueden adscribirse a este horizonte, como es el caso del nivel inferior del Castillo de Cardeñosa, al noroeste de Las Cogotas (DELIBES, G., 1995a: 67) o los más numerosos identificados, en la cuenca baja, dentro de la provincia de Zamora, entre los que destaca Santioste en Otero de Sariegos. Precisamente este último yacimiento, situado en el entorno de la laguna de Villafáfila, nos ha ofrecido uno de los documentos más interesantes sobre la economía del horizonte que nos ocupa. En opinión de Delibes, podría tratarse de una auténtica factoría dedicada a la obtención de la sai (DELIBES, G., 1993). Este establecimiento, el único de su género excavado hasta el momento, obtendría la sal por condensación del agua salobre. Así se desprende de las grandes placas de hogar. de los hornos rectangulares excavados en el subsuelo y de una serie de pilas que pudieron haberse empleado para el almacenamiento de la salmuera, así como por la presencia de cilindros de arcilla cocida, existentes en todas las instalaciones de este tipo. Sus paralelos se encuentran en diversos yacimientos de la Europa continental y atlántica, la mayoria de ellos fechables ya en el Bronce Final o Primera Edad del Hierro. La importancia de Santioste es indudable pues, como ha apuntado Delibes, "todos los indicios sugieren que, a partir del comienzo de la Edad del Bronce un inesperado recurso, la sal, alcanzó a revolucionar la economía de los grupos humanos instalados en el entomo de las lagunas de Villafáfila....[y] no parece muy temerario suponer que existio un importante comercio de "panes de sal" (DELiBES, G., 1995a: 92).

$\mathrm{Si}$ las cerámicas (Figura 1.3) de estos grupos se caracterizan por la ausencia de ornamentación, y una tipología que evidencia una evolución de las series canpaniformes, asi como por una cierta presencia de los perfiles carenados, todo parece indicar 
que la metalurgia (Figura 1.1 y 1,2) está sustentada en el trabajo de cobre arsenicado con los que se elaboran tipos de la tradición campaniforme como punzones, hachas planas, puntas palmela y. más excepcionalmente, alabardas, las cuales nunca se han encontrado en asociación a otros materiales. Como novedad, con respecto al Horizonte Campaniforme, podemos hablar de la presencia de pequeñas cuentas de plata formando parte del ajuar de una tumba femenina localizada en las proximidades de la instalación salinera de Santiroste, una materia prima que, en estos momentos, está perfectamente documentada en el área argárica donde con frecuencia está presente en los ajuares de enterramientos femeninos, como en el caso de Santioste (DELiBES, G., 1993: 41).

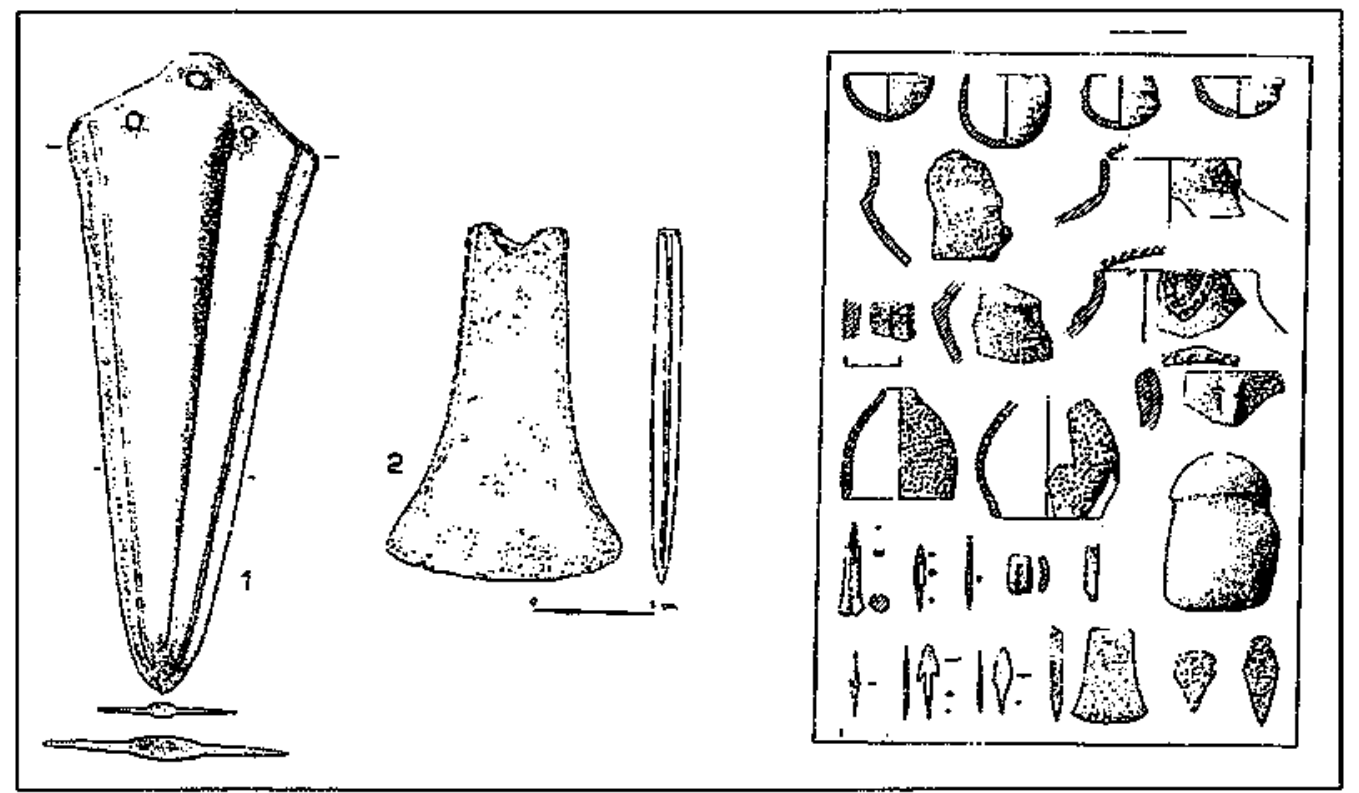

Figura 1.-Bronce Antiguo del Valle del Duero--1.1 Materales metálicos (Según Delibes 1995a) 1.2.-Diversos objetos del Castillo de Carderiosa (Sagún Delibes 1995b)

Otro aspecto destacable son las manifestaciones funerarias (Figura 2) tanto por su complejidad como por su heterogeneidad, si bien muestran una clara relación con el panorama que ofrece el Horizonte Campaniforme. En este sentido se explica la inhumación individual recuperada en las proximidades de Santioste (Figura 2.1), perteneciente a una joven, depositada en una fosa, en posición contraída y dotada con un ajuar compuesto por un cuenco cerámico liso, un brazal de arquero, y un collar formado por cuentas óseas, tres cápsulas de plata y un cierre con un botón de perforación en $V$ de marfil. Aunque la tumba y la fórmula de enterramiento, así como algunos de los elementos de ajuar, son similares a las campaniformes, la presemcia de materiales exóticos: marfil y plata, se valoran, como ya hemos apuntado, como signo de coetaneidad y parentesco con el mundo argá. rico, donde, tambiên las tumbas con joyas de plata, corresponden a mujeres, posiblemente pertenecientes al entorno familiar de la clase dirigente (DELIBES, G., 1993:41). 


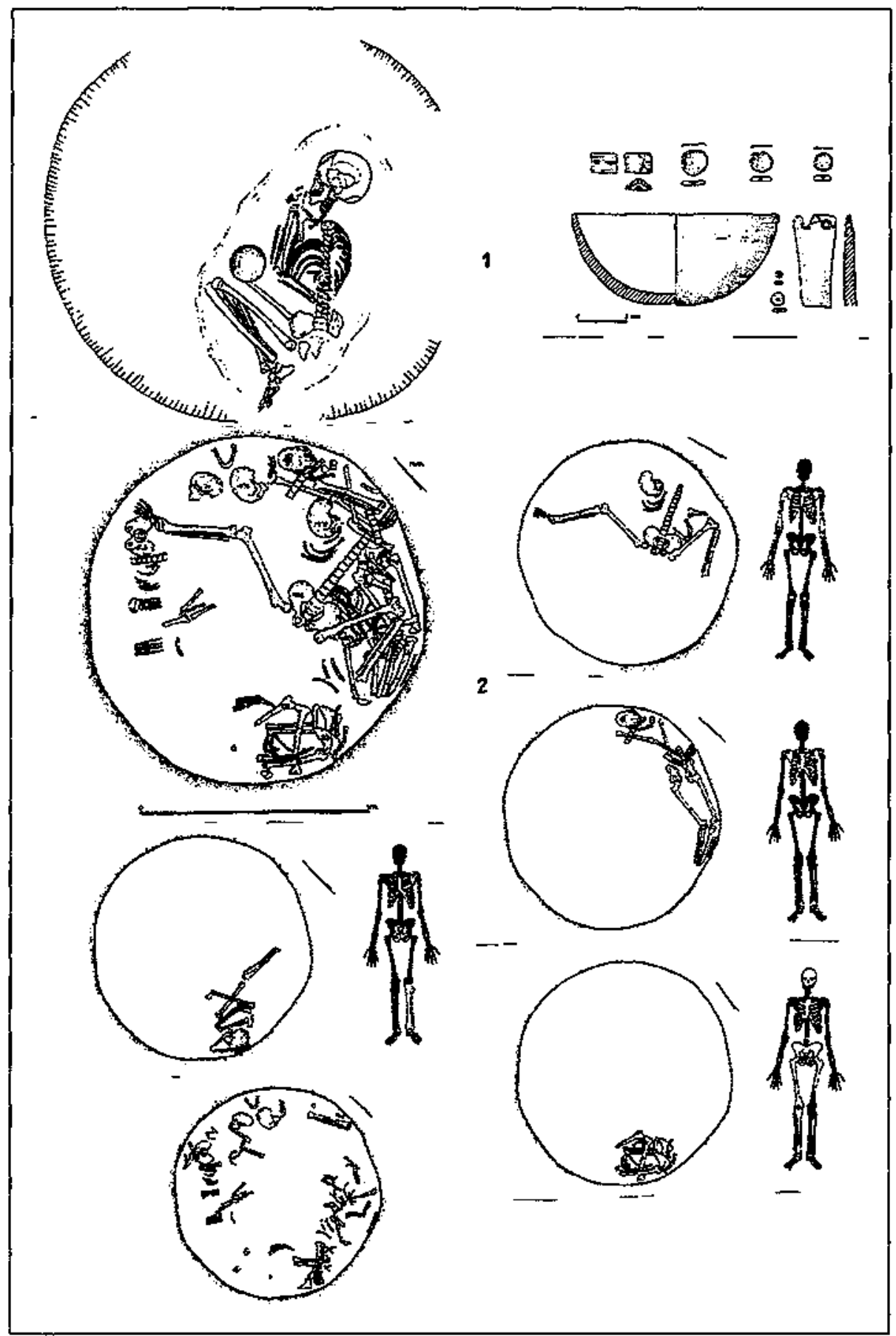

Figura 2.-Enterramtentos del Bronce Antiguo 2.1.-Santioste (Otero de Sariegos. Zamora) (Según Delịbes 1995a) 2.2.-El Tomillar (Bercial de Zapardiel. Avila) (según Fabián, 1995) 
Otro documento funerario que puede adscribirse a este horizonte es la necrópolis de Villalmanzo (Burgos) donde, unos trabajos de extracción de arcilla pusieron al descubierto los restos de, al menos, cinco inhumaciones, dos de ellas practicadas en grandes tinajas y las otras tres en cistas realizadas con lajas de caliza. Aunque las circunstancias que rodearon el hallazgo han impedido aislar los ajuares, los materiales recuperados son cerámicas lisas y un puñal de lengüeta, los cuales nos lievan a un ambiente similar al del Bronce Antiguo de otras áreas peninsulares. En concreto, nos encontramos con elementos del Horizonte Campaniforme: el puñal de lengüeta y ciertos paralelos con el área argárica: enterramientos en pithoi (DELIBES, G., 1971).

Frente a estas tumbas individuales continua el uso de megalitos y cuevas. Además parece confirmarse la práctica de otros enterramientos colectivos, como el del "Tomillar (Bercial de Zarpadiel, Ávila) (Figura 2.2), donde una fosa sirvió de alojamiento para la sucesiva deposición de cuerpos colocados en posiciones muy variadas e, incluso, se utilizó también como enterramiento secundario de restos óseos sin conexión anatómica. La falta de ajuares significativos y la total ausencia de metal dificultan la adscripción cultural de este hallazgo, aunque las tres fechas obtenidas (vid tabla 2), permiten incluirlo, al menos provisionalmente, en este horizonte del Bronce Amtiguo (FABÍN, J. F., 1995).

En la cuenca del Tajo, el Bronce Antiguo y Medio se identifica con el Horizonte Loma del Lomo, bien representado, de momento, en la Cuenca Alta, si bien recientes prospecciones en el Tajo Medio comienzan a entregar materiales que permiten intuir la existencia de un poblamiento similar al de las regiones más orientales. Como en la Cuenca del Duero, el poblamiento afecta tanto a las tierras llanas como a lugares elevados, aunque hay un interés especial por las zonas bajas, bien irrigadas situadas junto a los cursos fluviales, siguiendo una estrategia similar a la de los grupos campaniformes. con los que, a veces, coinciden en puntos muy próximos. Otro dato a considerar es el mayor tamaño de estos asentamientos frente a los campaniformes, lo que puede interpretarse por un aumento en el número de individuos que componen el grupo.

El prototipo lo representa el poblado epónimo de La Loma del Lomo (Cogolludo. Guadalajara), que se identifica con el carateristico asentamiento de "hoyos" (Figura 3.1). carente de un suelo de ocupación. Faltan además indicios de pies de postes y de muros que puedan ayudarnos a delimitar la forma y tamaño de las posibles cabañas. Por otra parte resulta dificil interpretar la función primaria de las fosas, ya que su contenido suele ser poco significativo, si bien algunos de estos hoyos debieron de servir como silos o despensas, depósitos de materiales, etc. y excepcionalmente fueron destinados a enterramientos, ubicados dentro del espacio doméstico. Así mismo, según se desprende de los materiales obtenidos dentro de las hoyas, en los poblados, se llevaban a cabo determinadas tareas cotidianas como la molienda y actividades industriales como la metalurgia, a juzgar por los fragmentos de recipientes hornos documentados en yacimiento madrileño de Tejar del Sastre (Blasco, C., y RoviRA, S., 1992-93).

A partir de este horizonte se generalizan los mencionados poblados de hoyos y es ahora cuando dichos hoyos alcanzan mayor capcidad y concentración las cuales se mantendrán a lo largo del Horizonte Cogotas I, particularmente, en la fase Protocogotas. Es 


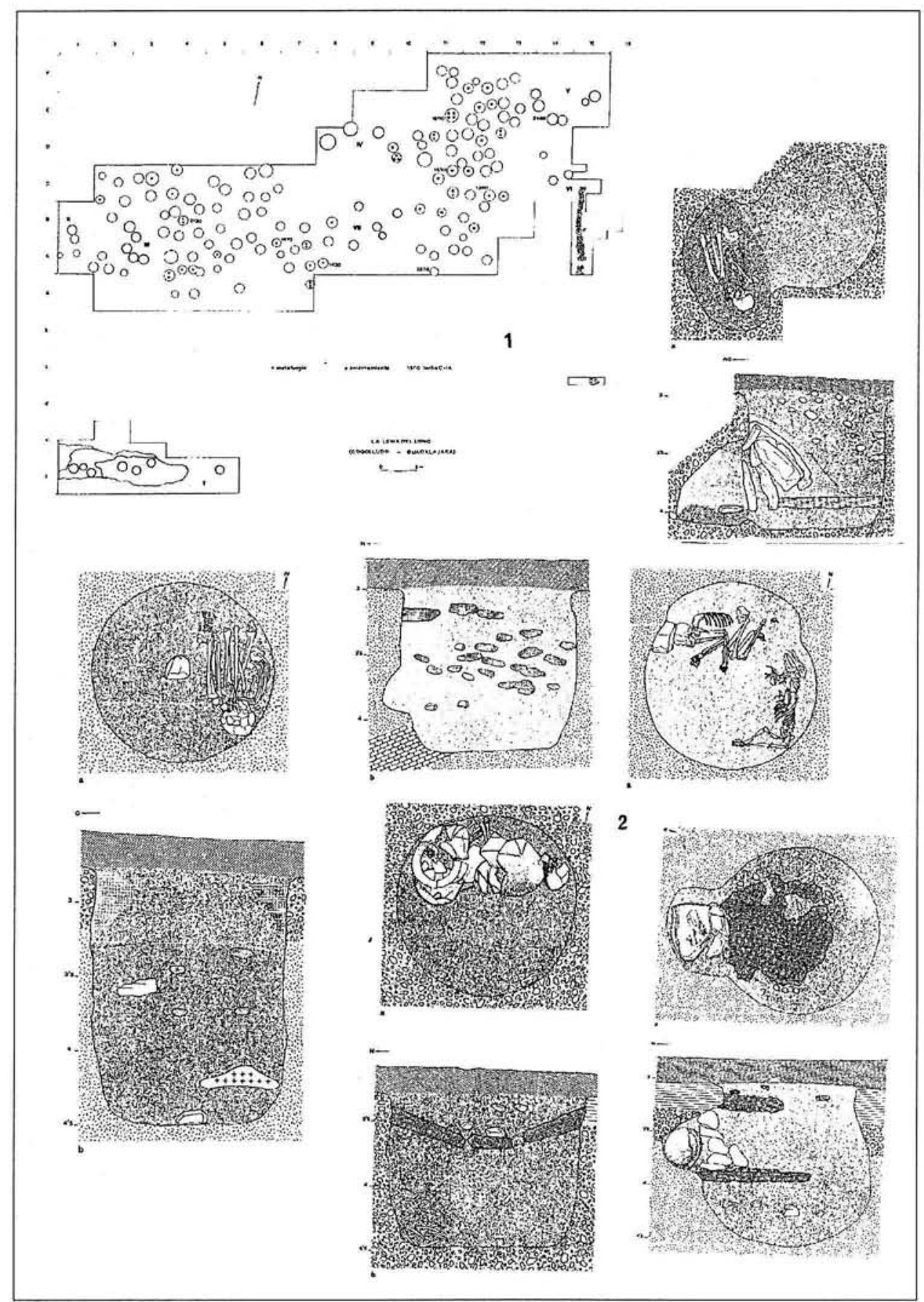

Figura 3.-La Loma del Lomo (Cogolludo, Guadalajara). 3.1.-Planta del poblado (Según Valiente 1995). 3.2.-Diversos tipos de enterramientos en fosa de La Loma del Lomo. (Según Valiente. J., 1992) 
probable que este hecho haya que interpretarlo, en paralelo con el Horizonte Parpantique, como consecuencia de la necesidad de almacenamiento de una importante producción de excedentes. La carencia de estructuras en duro aleja a estos establecimientos "de silos" de los patrones urbanisticos más conocidos de los yacimientos en altura del área argárica e. incluso, de las características arquitectónicas de los asentamientos en bajo de este círculo cultural, en los que predominan las estructuras domésticas de planta rectangular (AYALA, M. ${ }^{2}$ M., 1991: 74-98), una circunstancia que puede hacerse extensiva también a las motillas, en torno a las cuales debieron de existir áreas de poblamiento caracterizadas por viviendas dispersas de gran tamaño con planta rectangular u oval (NÁJERA, T., 1984: 11).

El material más habitual es el cerámico (Figura 4.3 y 4.4), entre el que son frecuentes los perfiles carenados, con la linea de carena situada a media altura o en un punto bajo del perfil y los acabados espatulados; las únicas decoraciones de estos recipientes carenados son aplicaciones plásticas de mamelones. muchas veces dispuestos en la línea de carena. Entre los contenedores de gran tamaño son frecuentes los perfiles ovoides y las decoraciones de cordones lisos o con impresiones, a veces bastante profusos, que recuerdan a produciones del Bronce valenciano.

La metalurgia (Figuras 4.1 y 4.2 ) recuperada en estos contextos es muy escasa y responde a los mismos tipos arcaizantes que ha entregado el Valle del Duero (puntas de pedúnculo, punzones, punales de lengüeta, hachas pianas), la existencia de una alarbada tipo Carrapatas, recuperada en el entorno del Manzanares, permite intuir relaciones con la metalurgia atlántica (BLAS, M. A. de, 1981) con una salvedad: en La loma del Lomo algunos de los objetos han sido realizados ya en un bronce binario (VAliENTE. J, 1992,b). Otro aspecto que interesa destacar es la categoria de los objetos mencionados pues mientras los punzones y hachas pueden considerarse útiles domésticos, la alabarda tipo "Carrapatas" de las terrazas del Manzanares y el puñal de Torrecuadrada (Guadalajara) pertenecerian a la categoría de objetos de prestigio, y es muy probable que formaran parte de ajuares pertenecientes a personajes destacados, un hecho frecuente en el mundo funerario campaniforme y quizás de los comienzos de la Edad del Bronce, si bien ya en el Bronce Pleno. como luego veremos, tanto los objetos de metal como los conjuntos vasculares que forman parte de los ajuares corresponden a la categoría de útiles cotidianos.

Tanto el Tejar del Sastre como La Loma del Lomo, han proporcionado no sólo piezas acabadas, sino también indicios complementarios de actividad metaluirgica. Concretamente en el fondo 59 del Tejar del Sastre (QUERO, S., 1982: 232-33), junto a cerámicas comunes amortizadas, se recuperaron varios fragmentos con adherencias de mineral, que indican que los procesos de calentamiento se hacian en recipientes-hornos similares a los utilizados en el Horizonte Campaniforme de la región (ROVIRA, S. 1989), para to cual no se requería ninguna infraestructura inmueble por lo que podía ejecutarse incluso en establecimientos de corta duración. Desgraciadamente la falta de análisis nos impide conocer si estas adherencias son de cobre o corresponden a un bronce binario. En la Loma del Lomo (VALIENTE, J., 1992a: 188), se recuperaron también crisoles o recipientes con adherencias de mineral así como un molde para fundir hachas, además de una costra de fundición obtenida en una fosa de enterramiento de una "anciana de 60-70 años, posiblemente como elemento de ajuar" (VALIENTE, J., 1992a: 187), aunque tampoco hay analitica de las adherencias de mineral. 


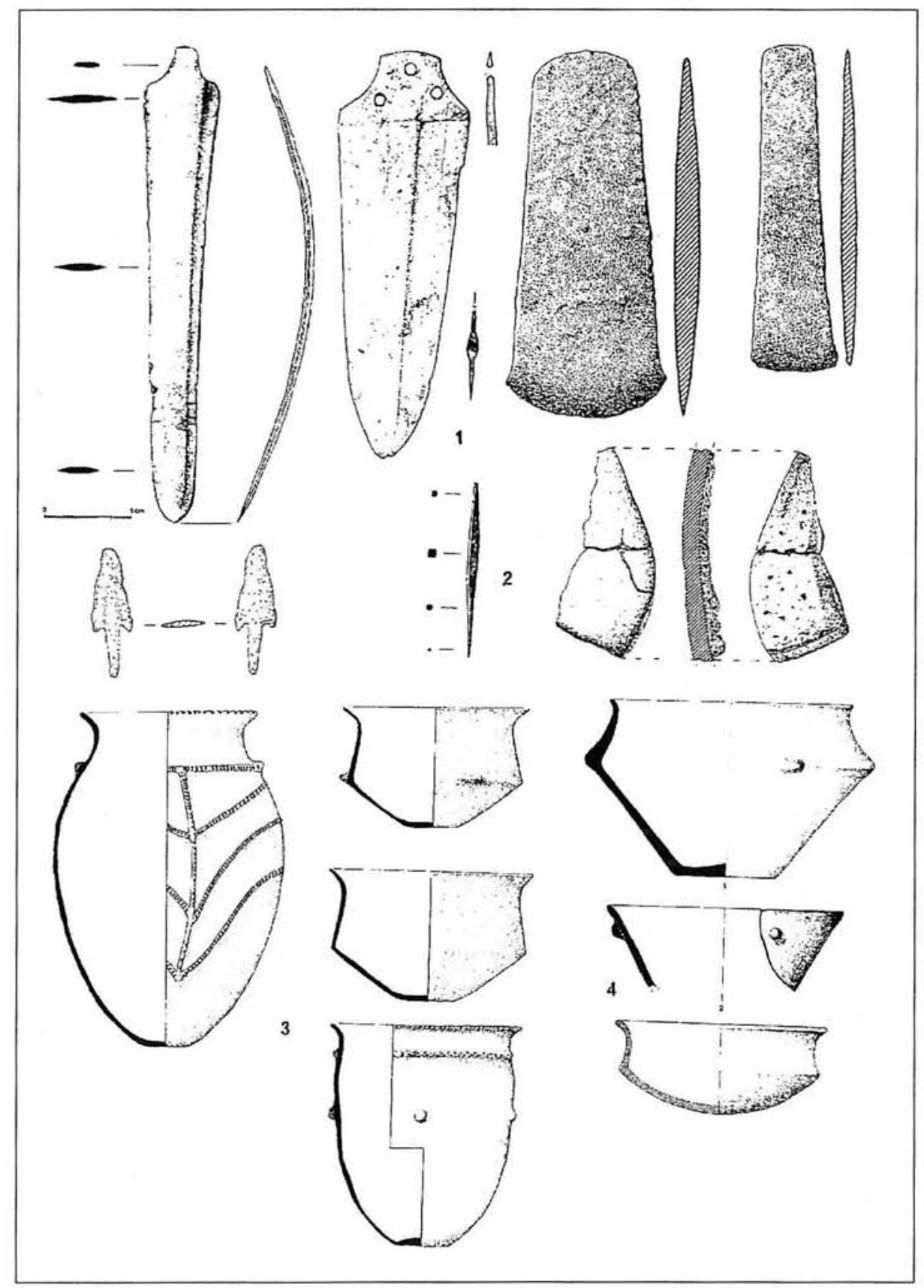

Figura 4.-Metalurgia y cerámica del Bronce Antiguo del Valle del Tajo. 4.1.-Diversos objetos metálicos descontextualizados (según Valiente, 1992, de Blas, 1981 y Almagro, 1955-57).

4.2.-Hallazgos en poblados (Según Blasco y Rovira 1992-1993). 4.3.-Cerámicas de La Loma del Lomo (Según Valiente, J., 1992) . 4.4.-Cerámicas de diversos yacimientos de la provincia de Toledo (según Carrobles, J., y otros, 1994) 
El material lítico denuncia la perduración de la talla laminar, aunque en menor proporción que en los horizontes previos, ya que son mayoria los útiles realizados sobre lascas anchas y amorfas. Entre los objetos elaborados destacan, por su número, los elementos de hoz que en la etapa de Cogotas I será prácticamente el único útil tallado.

Con respecto al ritual funerario, al igual que ocurre en el valle del Duero, se mantienen en uso determinados lugares de enterramiento tradicional, empleados para inhumaciones de carácter colectivo, como pueden ser los megalitos y las cuevas o grietas naturales, pero su vitlización parece más escasa que en horizontes anteriores. Entre las muiltiples cuevas meseteñas que pueden contener enterramientos de la Edad del Bronce se encuentran la de Pedro Fernández en Madrid. Pero es la Cueva del Fraile, en Uclés, Cuenca, la que ha entregado enterramientos más característicos de la edad del Bronce al encontrarse, varios de ellos, dentro de tinajas. En unos casos, como Estremera, estas cuevas de enterramiento se encuentran proximas a los lugares de hábitat, mientras que en otros, desconocemos su posible vinculación a un determinado asentamiento. A diferencia de la Meseta Norte, no se han documentado posibles monumentos utilizados en este momento como panteones colectivos.

Por el contrario los enterramientos mejor conocidos son las tumbas individuales o dobles, cavadas en el interior de los poblados (Figura 3.2). En La Loma del Lomo (VALIENTE J., 1987, 1990 y 1995), es donde se ha localizado un mayor número de enterramientos, éstos se concentran en el sector nororiental pero dentro de él se distribuyen aleatoriamente. Otros asentamientos de fosas o silos donde se han documentado este mismo tipo de enterramientos son El Tejar del Sastre, (QUERO, S., 1982) o el de la Fábrica de la Compañia Euskalduna-El Espinillo (Almagro BaSCH. M., 1960, y BaQUEDano, M." I. y BLANCO, F., 1994), ambos en la cuenca dei Manzanares y pertenecientes al municipio de Madrid.

En otros casos, los restos funerarios han aparecido descontextualizadios o, al menos, sin relación con asentamientos, bien por tratarse de hallazgos ocasionales a los que no ha seguido una excavación que permitiera poner esos restos en relación con su entorno, caso de los areneros del Jarama, Quitapenas y Presa del Rey, bien porque en el proceso de excavación no se ha localizado el poblado, caso del Cerro del Obispo del Castillo de Bayuela (Toledo), aunque, según sus excavadores, esta necrópolis "corresponde a un poblado instalado en el cercano Cerro Castilla" (GiL, J. I., y otros, 1988) A ella habría que sumar los enterramientos en Cueva, como la del Fraile, Uclés (Cuenca). localizados tanto a la entrada como en el interior de la cueva.

La morfología de las tumbas en fosa nos permite agruparlas en dos tipos:

a) De planta netamente circular u oval. Entre los yacimientos con esta tipología de tumbas se encuentran: La Loma del Lomo (VALIENTE, J., 1992) 3, La Presa del Rey (GEANINI, A., 1991) Arenero del Manzanares (GAIBAR, C., 1974. 250), Fábrica de Euskalduna-El Espinillo (AlmaGro BASCH, M., 1955, y BAQuEDANO, M. ${ }^{2}$ I. y Blanco, F., 1994) y El Tejar del Sastre (QUERO, S., 1982). b) De planta circular en la boca, pero con un nicho abierto en 
la zona inferior de pared donde se coloca el cuerpo del difunto. Se han documentado en La Loma del Lomo (VALIENTE, J., 1992) Es una variante conocida también en el ârea argárica, concretamente a esta tipología pertenecen las cuatro tumbas documentadas en los cortes 4 y 5 de La Cuesta del Negro de Punallena donde, según sus excavadores, deben de tener una cronología muy próxima y, a juzgar por la tipologia del puñal que constituye el ajuar de la tumba 2, hay que relacionarlas "con el horizonte de los "pithoi" en El Argar y son, por tanto, de época tardia" (MOLINA, F, y PAREjA, E., 1975: 53).

La capacidad de ambos tipos de tumbas en fosa es muy variable si bien observamos que existe una amplia mayoría con un diámetro que oscila entre 1 ' 5 y 2 metros y una profundidad cercana al metro, unas dimensiones que se acercan mucho a las consignadas en La Cuesta del Negro de Purullena, lo que aumenta los paralelos entre los enterramientos de La Meseta y este yacimiento argárico. En estas fosas los cuerpos son depositados con orientaciones variables y posición más o menos contraída. Generalmente se colocan en el fondo de las fosas, sin preparación previa, descansando sobre un lateral mirando, indistintamente, hacia el centro de la fosa o hacia la pared junto a la que se han depositado. Pueden alojarse directamente, o dentro de un "pithos", en la fosa o en un nicho lateral.

En la cuenca del Tajo ei número de hallazgos de enterramientos en tinaja aumenta día a día, entre los yacimientos conocidos hace ya tiempo se encuentran el arenero Quitapenas (PÉREZ DE BARRADAS, J.. 1936), El Tejar del Sastre (Quero. S., 1982: 138) y La Fábrica de Euskalduna (AlmaGro BASCH, M., 1960). los tres dentro del término de Madrid, también se ha documentado en los areneros del Jarama (Rivas-Vaciamadrid) (GAiBAR, 1974). Más recientemente se han dado a conocer los importantes hallazgos de la Loma del Lomo en Cogolludo (Guadalajara) (VALIENTE, J., 1987, 1990 y 1993), que evidencian la preferencia de uso de esta modalidad de enterramiento en tinaja para las inhumaciones infantiles (Figura 3.a, b y c). Sin embargo el área de presencia de este tipo de manifestaciones se ha ampliado al Tajo Medio en la necrópolis del Cerro del Obispo en Castillo de Bayuela (Toledo) (GIL, J. I., y otros, 1988) y a la cuenca del Júcar, donde el Cerro Pelao de Tébar (Cuenca),entregó un enterramiento infantil en pithos, dentro del ámbito del poblado (DIAZ-ANDREU, M., 1994: 150). No cabe duda que esta modalidad de enterramiento en tinaja vuelve a aproxirnar el mundo funerario del Bronce meseteño al área argárica y permite certificar que dichos contactos son anteriores a la presencia de las características cerámicas Cogotas 1 .

Una modalidad distinta la encontramos en el Cето del Obispo donde los "pithoi" aparecen en una caja de bloques graniticos, formando seudocistas dentro de las cuales se encuentra el ajuar que incluye no sólo recipientes cerámicos y restos animales sino también algunos elementos de adorno, una circunstancia que coloca a este cementerio toledano más cerca de las manifestaciones funerarias del Cerro de La Encantada (CARROBLES, J., y otros, 1994: 96) y, en general de la región manchega. Otra casuística ofrecen los hallazgos de la Cueva del Fraile (Cuenca), el único caso conocido en el que los pithoi aparecen dentro de este tipo de marco. En dicha cueva, además de diez inhumaciones existentes a su entrada, se documentaron, en una zona más profunda, otras "cinco in- 
humaciones en pithoi, acompañadas de conchas, marfil, punzones de hueso y un fragmento de amianto. En esta sala se localiza por primera vez trigo y restos óseos de ciervo, buey y caballo" (DIAZ-ANDREU, M., 1994b: 151).

Aunque la mayoria de las tumbas son individuales existen algunas dobles y hasta triples como la hoya $11 \mathrm{E}-2$ de La Loma del Lomo donde se documentó una triple inhumación infantil junto a la de una mujer de entre 14 y 16 años de las que, al menos dos de ellas, (la de la mujer y la de uno de los niños), presentaban los huesos "alterados", "porque el enterramiento ha sido removido o porque la deposicion se hizo de forma violenta" (VALIENTE. J., 1987: 117), si bien no puede descartarse que se trate de enterramientos secundarios. Otro aspecto a destacar es la reiterada intencionalidad en la cubrición de los cuerpos con la acumulación de bloques de piedra, no visibles en la superficie. Este fenómeno es especialmente notable en el caso de las fosas con nicho cuyas bocas se sellan con numerosos bloques de piedras de gran tamaño (Figura 3.2).

La mayoria de los enterramientos o carecen de ajuar o se acompañan únicamente đe algún vaso cerámico o, algun punzón de cobre o hueso o, incluso, de objetos domésticos amortizados, tales como restos de fundición, crisoles, fragmentos de coladores, etc.. A todo ello hay que sumar la frecuente incorporación de restos animales, bien en grandes porciones, bien individuos completos. Se trata, sin duda, de la ofrenda más generalizada y específica que incluye no sólo animales dedicados al consumo sino tambiên algunos cánidos. Más excepcionalmente aparecen conchas marinas, un dato de importancia por revelar la existencia de contactos a "larga distancia".

En La Loma del Lomo los restos animales pertenecen, sobre todo, a suidos, con frecuencia inmaduros, que se depositaron completos, entre ellos merecen especial referencia los hallazgos de la hoya 12E-2 donde se encontraron los restos de un suido neonato "protegidos o enmarcados" con media cazuela carenada y asociado a los cuartos traseros de un bóvido y a una segunda cazuela carenada completa de excelente calidad (VALIENTE, J., 1993: 256-7). Se trata de un documento singular que testifica la asociación de contenedores cerámicos a sacrificios animales. J Valiente, ha planteado una sugerente hipótesis sobre el posible significado de estas "ofrendas de suidos" en asociación a granos, como rituales relacionados con la fertilidad (VALIENTE, J., 1993) En otros yacimientos, junto a suidos se han encontrado también, en proporciones importantes, ovicápridos, bóvidos y perros, lo que permite suponer que existan otras explicaciones a estos depósitos, además de la esgrimida por J. Valiente. Un ejemplo singular, lo constiuyen los depósitos de las tumbas de El Cerro del Obispo del Castillo de Bayuela donde, a las cerámicas y útiles cotidianos, como industria lítica o crisoles, se unen las ofrendas animales comunes al resto de los yacimientos $y$, algún objeto personal aislado como un brazal de arquero y un supuesto "ídolo de cuernos" (MENÉNDEZ, M. L., y otros, 1988: 103), pero faltan las armas.

Aun sin entrar en un análisis pormenorizado, todo parece indicar que la riqueza de los ajaures y el volumen de carne y de piezas depositadas no están en función de la edad o sexo de los individuos, antes bien entre los ajuares más importantes se encuentran los de varias tumbas infantiles por lo que podría inferirse que estamos ante unas 
sociedades entre las que el prestigio se encuentra unido al parentesco, algo que se observa en el mundo argárico de plenitud y que en opinión de $V$ Lull implica "el paso de una sociedad cuyo sistema de funciones individuales se deben a la actividad, edad y representación de cada uno de sus miembros, a otra donde esos derechos se obtienen ." (LULL, V., 1983: 455) Al igual que en el mundo argárico de apogeo, un "núcleo de población importante se entierra sin ajuar, pero, a diferencia de él, en la Meseta no existen elementos de contenido ideológico, excepción hecha del Cerro del Obispo. Por el contrario, las desigualdades suelen estar marcadas por un mayor o menor contenido de ofrendas animales.

A veces estas ofrendas de animales aparecen sin relación directa con los enterramientos. colocados con todo cuidado, calzados con piedras y con las patas replegadas. en posiciones que se asemejan a las de los propios enterramientos humanos. En ocasiones, los depósitos consisten únicamente en grandes porciones, generalmente en cuartos traseros o delanteros o incluso partes más reducidas del esqueleto animal. Estos depósitos de animales no son patrimonio exclusivo del ámbito de la Meseta sino que están documentados también en yacimientos de otras áreas culturales peninsulares y extrapeninsulares de diversos momentos de la Prehistoria Reciente, como es el caso de Gran Bretaña donde tales depósitos son conocidos desde hace tiempo, en distintos yacimientos. Como en nuestro caso, aparecen "auténticos enterramientos de animales completos", siendo las especies más frecuentes el perro, los caballos y las aves, destacando entre ellas el caballo (CUNLIFFE. B., 1992: 75).

En suma, tanto en la Cuenca del Duero como en la del Tajo el Bronce AntiguoMedio, presenta no pocos rasgos que denuncian paralelos importantes con el círculo argárico, algo que está dentro de toda lógica si tenemos en cuenta las concomitancias entre ambas áreas duante el Horizonte campaniforme así como los indudables contactos durante el Horizonte Cogotas I, unos contactos que también parecen haberse producido entre la Meseta y otras regiones periféricas. Fenómeno que permite explicar la relativa simetría que encontramos entre los diversos desarrollos locales.

\section{EL INICIO DEL HORIZONTE COGOTAS I}

Desde mediados del segundo milenio la existencia del Bronce Pleno está totalmente consolidada ya en todo el extenso espacio geográfico que nos ocupa. En estos momentos, junto a la persistencia de círculos ya formados, caracterizados por conjuntos vasculares lisos, dotados de carenas más o menos acusadas, se origina el Horizonte Cogotas I en torno a las cuencas de los ríos Duero y Tajo, cuya etapa de formación (Protocogotas I o Cogeces) bien fechada en la Meseta Norte, ha podido también ser datada en el yacimiento de Perales del Río (Getafe, Madrid), en la cuenca alta del Tajo, confirmando la sincronia entre ambas cuencas. Las fechas contexualizadas en esta etapa Protocogotas son las siguientes: 


\section{TABLA 3}

\begin{tabular}{|c|c|c|c|c|c|c|}
\hline Yacimiento & Laboratorio & bp & ane & cal ane & \pm & Etbliografa \\
\hline \multicolumn{7}{|l|}{ CUENCA DEL DUERO } \\
\hline Los Toirnos & C.S.I.C. 409 & 3360 & 1410 & 1668 & 50 & Castro, Lull y Mico 1996 \\
\hline Los Tolmos & C.S.I.C. 408 & 3370 & 1420 & 1676 & 50 & Castro. Lull y Micó 1996 \\
\hline Los Tolmos & C.S.I.C. 480 & 3380 & 1430 & 1682 & 50 & Castro, Lull y Mícó 1996 \\
\hline Los Tolmos & C.S.IC. 443 & 3360 & 1410 & 1668 & 50 & Castro, Lull y Mícó 1996 \\
\hline Los Tolmos & C.S.I.C. 442 & 3380 & 1430 & 1682 & 50 & Castro, Lull y Micó 1996 \\
\hline El Balconcillo & & & 1480 & & 60 & De la Rosa, 1995 \\
\hline El Cogote & Gr N 18873 & 3330 & 1385 & 1650 & 35 & Castro. Lul! y Micó 1996 \\
\hline El Cogote & Gr N 18874 & 3415 & 1465 & 1716 & 40 & Castro. Lull y Mico 1996 \\
\hline La Corvera & & 3315 & 1365 & 1587 & 25 & Castro. Lutl y Mico 1996 \\
\hline La Corvera & & 3355 & 1405 & 1655 & 25 & Castro, Lull y Micó 1996 \\
\hline La Venta & & 3100 & 1150 & 1382 & 50 & Castro, Lull y Micó 1996 \\
\hline La Venta & & 3300 & 1350 & 1583 & 35 & Castro, Lull y Micó 1996 \\
\hline La Plaza (Cogeces) & Gr N 10.617 & 3275 & 1325 & 1560 & 30 & Castro. Lull y Micó 1996 \\
\hline La Plaza (Cogeces) & Gr N 14.560 & 3275 & 1325 & 1560 & 30 & Rodriguez y Abarquero. 1994 \\
\hline Carrelasvegas & Beta 51508 & 3230 & 1280 & & 80 & Martin y otros. 1993 \\
\hline La Huelga & Beta 71373 & 3080 & 1130 & & 60 & Pérez Rodriguez y otros, 1994 \\
\hline Cueva de Arevalillio 4 & C.S.I.C. 400 & $3290^{*}$ & 1340 & 1576 & 50 & Castro, Lull y Mico 1996 \\
\hline Cueva de Arevaillto & C.S.I.C. -422 y 423 & $3300^{*}$ & 1350 & 1581 & 50 & Castro, Lull y Micó, 1996 \\
\hline \multicolumn{7}{|l|}{ CUENCA DEL TAJO } \\
\hline Caserio de Perales & CSiC-1089 & 3356 & 1406 & 1629 & 68 & Blasco y otros, 1995 \\
\hline
\end{tabular}

Teniendo en cuenta los datos que proporciona esta tabla, y exceptuando el pro* blema que ofrece el yaimiento de La Huelga, cuyas dos muestras (una de ellas perteneceiente al horizonte campaniforme) resultan excesivamente modernas, hay que admitir que, salvo una de las dataciones de La Venta, el resto, encaja dentro de una horquilla muy concreta: $1465-1280$ a. C., que en fechas calibradas se eleva a 1716-1480, marco temporal en el que habría que situar la etapa de formación de Cogotas I. Como puede desprenderse de una simple comparación con las fechas del Bronce Pleno de cerámicas lisas, ambas tradiciones pudieron llegar a ser sincrónicas, al menos en algunas zonas, una circunstancia que no resulta sorprendente si se tiene en cuenta los rasgos comunes que comparten: tipos de asentamientos, arquitectura o manifestaciones funerarias. Además, podemos hablar de una unidad cultural entre las tierras de las dos cuencas fluviales, si bien la posición geográfica de la cuenca del Duero explica la mayor vinculación de esta

\footnotetext{
${ }^{4}$ Las fechas con asterisco correponden a niveles con materiales Cogotas I y canpaniforme.
} 
región con los focos metelúrgicos del atlántico y, muy especialmente, con el noroeste. Ahora las relaciones entre el sureste y la Meseta se detectan no sólo por la presencia de elementos de filiación "argárica" en las tierras del interior, sino también por la existencia en yacimientos meridionales de cerámicas con las características decoraciones Protocogotas, como es el caso de Peñalosa (Contreras, F., 1995) o Setefilla (AuBeT. M. ${ }^{a}$ E. y otros, 1983) Estas evidencias quizás no haya que interpretarlas como una irrupción de las gentes de la Meseta en regiones periféricas sino como signo de una continuidad de contactos que ahora se hacen más evidentes por la singularidad de un determinado estilo cerámico.

En el valle del Duero el poblamiento se carateriza por mantener la gran diversidad que se había iniciado en el Bronce Antiguo, de manera que, junto a una ocupación residual de las cuevas, encontramos establecimientos en altura, con importantes defensas naturales completadas con recintos arquitectónicos que protegen las zonas más vulnerables, como en el Castro de La Plaza en Cogeces del Monte (DELiBES, G. y FERnÁNDEZ MANZANO, J., 1981) Sin embargo, el tipo de hábitat más habitual corresponde a los establecimientos en bajo, en la terraza inferior de los ríos, en zonas bien irrigadas y sin ninguna preocupación por la defensa. Desde el punto de vista arquitectónico, se generaliza ahora el modelo de los poblados de hoyos, ya abundantes en el Tajo durante la etapa anterior, los cuales carecen de defensas y no conservan, salvo excepciones, restos de las cabañas, sino únicamente los abundantes hoyos excavados en el subsuelo donde aparece concentrado el material. Desgraciadamente la falta de suelos de ocupación y de las plantas de las cabañas nos impide conocer su distribución espacial, la morfología de sus plantas y su tamaño, asi como la relación topográfica con los "hoyos" excavados en el subsuelo. Por otra parte, hasta ahora son muy pocos los yacimientos de este tipo excavados en extensión y muchos menos los publicados de manera sistemática por lo que la documentación con la que contamos resulta bastante parcial.

Un dato a tener en cuenta es la relativa frecuencia con la que encontramos yacimientos que han sufrido una reiterada ocupación a lo largo de distintos momentos del Horizonte Cogotas I, aunque estamos lejos de conocer el ritmo de estas reocupaciones, el porqué de la insistencia en la ocupación de determinados puntos o la duración de los posibles periodos de abandono. Entre los yacimientos adscribibles a esta etapa de formación pueden citarse: Carrelasvegas (MARTín, M. A., y otros, 1993) y La Venta (PÊREZ RODRígueZ, J. F., y FERNANDEZ GMENEZ, J. M.. ${ }^{2}$ 1993) , en la provincia de Palencia, Las Empedradas (Burgos) (Palomino, A. L., y Rodríguez Marcos, J. A., 1994), El Cogote (CABALlERO, J.: PORRES, F., y SAlAZAR, A., 1993), La Gravera de Puente Viejo (GONZÁLEZ TABLAS, J., 1984-85) y Zorita de los Molinos (GONZÁlEZ TABLAS, F. J. y LARRén, H., 1990) en Avila o El Carrizal (RoDrfGueZ MARCOS, J. A., 1993) en Valladolid. Otros yacimientos como Los Tolmos de Caracena (Soria) (JMENO, A., 1984, y JIMENO, A., y FERNÁNDEZ MORENO, J. J., 1992,b), El Cementerio-El Prado (Valladolid) (RoDRígueZ, j. A., y ABARQuero. J , 1994) o La Huelga (Palencia) (MISIEco, C., y otros, 1992) parecen haber sido objeto de distintas ocupaciones que abarcan un lapso temporal relativamente amplio que, en 
El mundo funerario mejor conocido se asocia a los poblados y está representado por los enterramientos individuales y más excepcionalmente dobles o triples en fosas localizadas junto a las cabañas. Concretamente en Los Tolmos de Caracena (Figura 8.1) se han exhumado dos de estas fosas. En una de ellas, situada en el exterior de una de las cabañas, se recuperó un cuerpo en una posición forzada conseguida mediante ataduras, en la segunda se encontraron tres cuerpos: dos adultos (hombre y mujer) y un neonato. Otro asentamiento que ha proporcionado este tipo de manifestaciones es el de Carrelasvegas donde una de las nueve fosas excavadas contenía una inhumación, en posición contraida, colocada junto a la pared del hoyo, así como otros restos óseos sin conexión anatómica, posiblemente resultados de enterramientos secundarios (MARTíN, M., A. y otros, 1993). Son enterramientos que mantienen las fórmulas de la etapa anterior y que tienen como denominador común la ausencia de ajuares ya que el material recuperado son piezas amortizadas, pero no se ha documentado la utilización de pithoi, a semejanza de algunas sepulturas del horizonte anterior.

En esta etapa los paralelos entre el Valle del Duero y el del Tajo resultan más estrechos que en momentos previos, ya que en la cuenca del Tajo se mantienen vigentes los poblados de "hoyos" que se habían generalizado en el Bronce Antiguo y entre los que son frecuentes las reiteradas ocupaciones que pueden llegar a abarcar todo el Horizonte Cogotas I, aunque desconocemos la duración de las etapas de abandono. Los lugares preferentes siguen siendo las terrazas bajas de las cuencas inferiores de los ríos. en puntos próximos a donde se ubican las ocupaciones campaniformes y del Bronce Antiguo, pero no faltan ejemplos de ocupaciones en los altos cursos fluviales, como Las Canteras de Zarzalejo (FERNANDEZ VEGA, A., 1980). El yacimiento más singular es el Caserio de Perales, que pudo llegar a extenderse por una amplia superficie de varias hectáreas y del que se ha excavado algo más de una hectárea (Figura 6.1) en la que se identificaron más de 500 "hoyos" pertenecientes a una buena parte de la secuencia de Cogotas I, aunque la etapa mejor representada es precisamente la fase Protocogotas. La distribución de los materiales indica que las distintas ocupaciones coincidieron sólo parcialmente en una determinada área del asentamiento.

Este yacimiento ubicado en el término de Getafe (Madrid), ha evidenciado la práctica de la molienda, con abundantes molinos realizados sobre granito procedente de unos 40 kilómetros de distancia y actividades industriales, como la metalurgia, el tejido - la talia lítica ya que ha ofrecido goterones de mineral procedentes de la fundición, pesas de telar de forma cilindrica y núcleos y lascas que permiten hacer un completo remontaje de las extracciones procedentes de un mismo nódulo Sobre esta industria lítica conviene apuntar la paulatina transformación en los sistemas de taila ya que el trabajo laminar se mantiene como una técnica residual minoritaria y, junto a ella, se producen objetos sobre lascas amorfas obtenidas de núcleos con extracciónes multidireccionales para conseguir un aprovechamiento más integral, una ténica que se mantedrá en la etapa de plenitud del horizonte. Entre los materiales recuperados destaca la cerámica, de características similares a la de la Meseta Norte, tanto por las técnicas y motivos ornamentales como por las morfologías entre las que están presentes acusadas carenas que tienden a ocupar una posición más alta (Figura 7.4). 


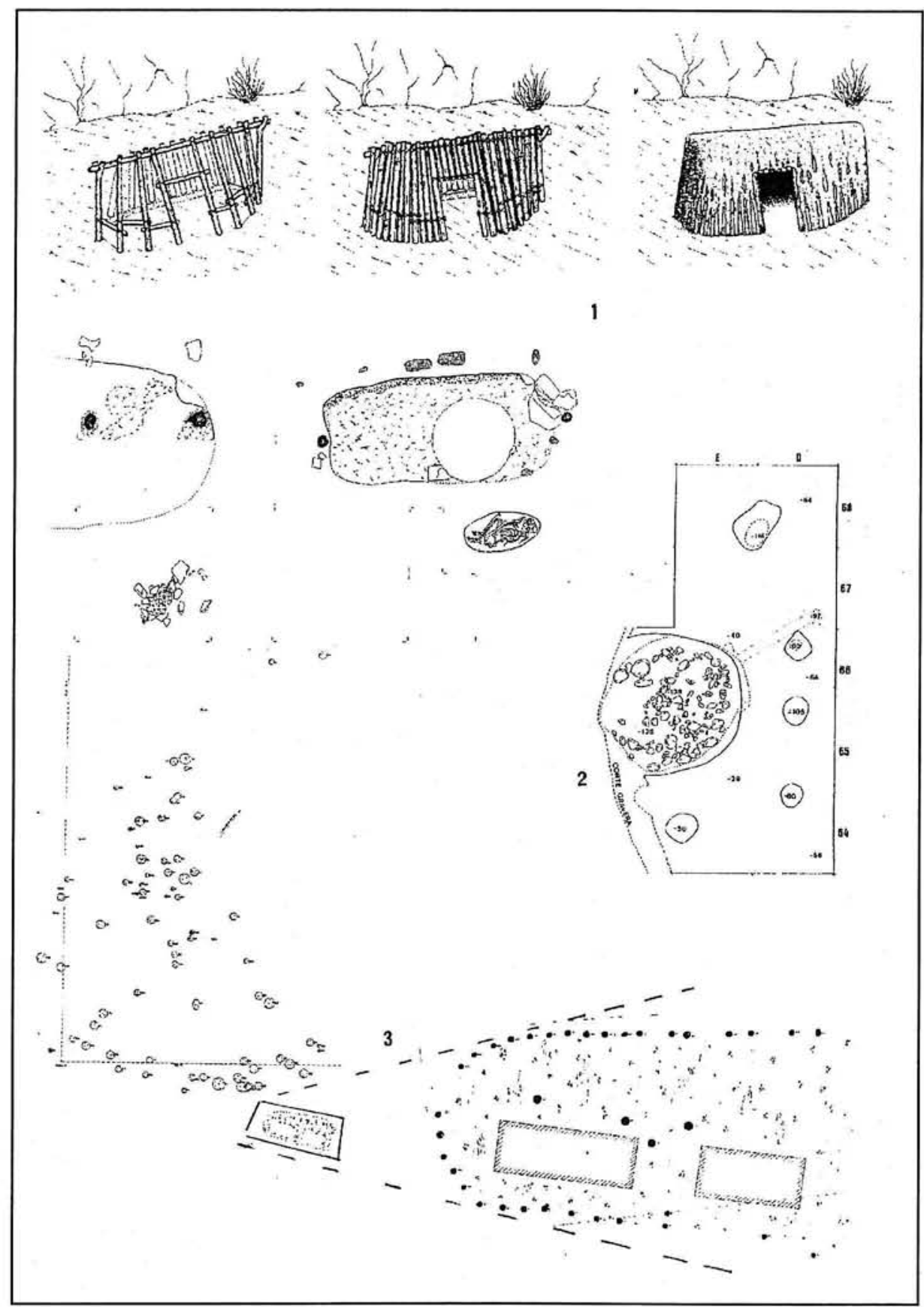

Figura 6. -6.1.-Reconstrucción y planta de una de las cabañas de Los Tolmos de Caracena con el enterramiento y hogar exteriores (Según Jimeno y Fernández Moreno 1991). 6.2.-Planta de un posible horno de cerámica de La Venta (Según Pérez Rodríguez y Fernández, 1993). 6.3.-Planta de Teso del Cuerno (Según Martín y Jiménez, 1988-89) 
Desde el punto de vista de la tecnología metalúrgica (Figura 71 a 7.3) supone la consolidación de los bronces de aleación binaria, según se desprende de la analítica practicada a los objetos recuperados en Perales del Río, (BLASCO, C., y ROVIRA, S., 199293) Entre los productos acabados de este yacimiento se encuentran varios punzones, una punta de pedúnculo y aletas de tipología próxima a la de La Loma del Lomo, un puñal de remaches y un fragmento de lo que pudo ser una varilla-lingote, la similitud tipológica con algunas de las piezas de La Loma del Lomo se acentúa por haber sido fundidas todas ellas en bronce, a excepción de la punta de flecha del Caserio de Perales que está realizada exclusivamente en cobre. Este panorama refleja que yacimientos de una misma área geográfica, con características arquitectónicas muy próximas, pero con conjuntos vasculares distintos que los identifican con círculos culturales diferentes, como son La Loma del Lomo y El Caserio de Perales, tienen una metalurgia técnica y morfológicamente similar. Por el contrario, yacimientos de áreas geográficas distintas como los Tolmos de Caracena, en el Alto Duero y el Caserío de Perales, en el Aito Tajo, con carcteristicas arquitectónicas y cerámicas muy próximas que los identifican con un mismo horizonte cultural: "Protocogotas", presentan un nivel metalúrgico distinto, ya que mientras en Los Tolmos de Caracena sólo se trabaja el cobre (JIMENO, A. y FERNÁNDEZ MORENO, J J., 1992a: 242) en Perales del Río, la mayoría de las producciones están elaboradas en bronces de buena calidad.

Dentro de este mismo horizonte metalúrgico y cronológico de la segunda mitad del segundo milenio en el que se encuadraria el horizonte protocogotas habría que incluir algunos hallazgos aislados como es el puñal de bronce de Casasola (VAlínTE, J , 1992, b: 44) y la espada del Arenero de La Perla de Madrid (PEREZ DE BARRADAS, J.,193335) (figura 7 1) Esta espada, de empalme semicircular con remaches y entalle y de hoja ancha y sin nervaduras, está próxima a algunos ejemplares procedentes del noroeste peninsular (ALMAGRO GORBEA. M., 1972) pero también puede ser sincrónica de la recuperada en la sepultura del estrato XIV de Setefilla donde se han documentado algunos fragmentos cerámicos con decoraciones típicas de las producciones vasculares Protocogotas (AUBET, M. ${ }^{2}$ E., y otros, 1983: 57). Desgraciadamente desconocemos si es de bronce o, como el ejemplar de Setefilla, está realizada en cobre, un hecho que contrastaría con la metalurgia del bronce documentada en el Caserio de Perales, pero tal diferencia no sería rara si pensamos que podemos encontrarnos ante una pieza de importación producida en talleres más o menos lejanos a la zona.

Al igual que los hábitats, los enterramientos mantienen fórmulas similares a las de la etapa anterior y a las documentadas en este mismo horizonte en la Meseta Norte. Nuevamente es el Caserío de Perales el yacimiento que sirve de referente. En él se recuperaron cinco fosas de inhumación (Figura 6.2), entre los restos de viviendas, de las cuales, cuatro parecen pertenecer al periodo Protocogotas. Tres son inhumaciones individuales y la cuarta corresponde a un enterramiento infantil doble. Todos los cuerpos se encuentran en posición contraída, con los brazos doblados hacia arriba y las manos apoyadas en el mentón. Dicha postura la encontramos así mismo en algunos de los enterramientos de La Cuesta del Negro de Purullena (vid figs. 14 y 15 en pp. 31 y 32 de MOLINA, F., 


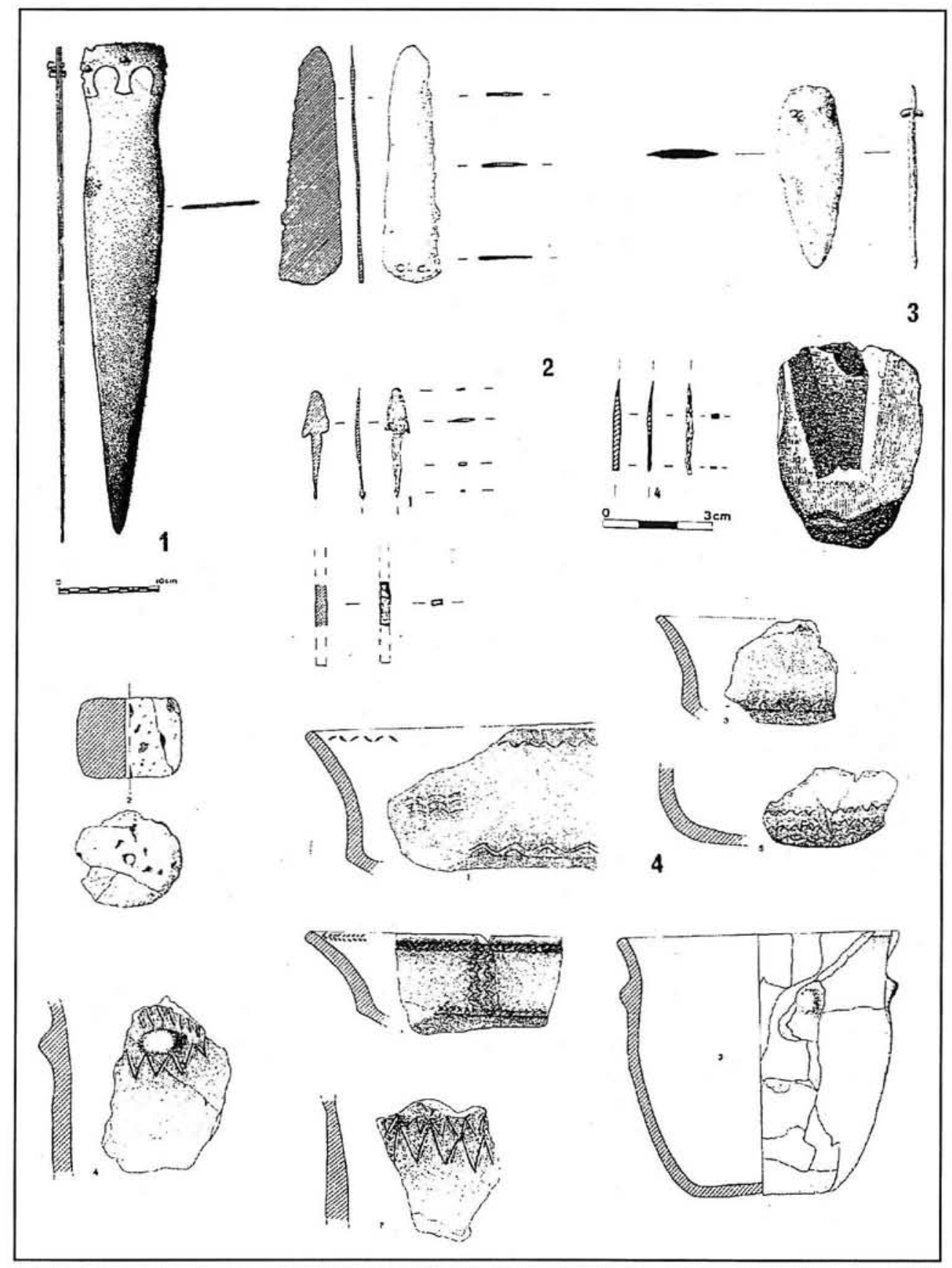

Figura 7.-Materiales Protocogotas del Valle del Tajo. 7.1.-Espada del Arenero de La Perla (dibujo E. Carrión) .7.2.-Metalurgia del Caserío de Perales (Según Blasco y otros, 1995) . 7.3.-Puñal de Casasola y Molde del Arenero de Fuente de La Bruja (Según Valiente, 1992 y Pérez de Barradas, 1926) 7.4.—Cerámicas del Caserío de Perales (Según Blasco y Otros, 1991) 
y PAREJA, E., 1975). Unos reposan en el centro de la fosa mientras que otros se alojan en un nicho abierto en la pared, estos nichos aparecen, como en La Loma del Lomo, sellados con grandes bloques de piedras, así mismo, algunos de los cuerpos colocados en el centro de la fosa están protegidos por una importante acumulación de piedras.

Poco sabemos de las características físicas de los enterrados, entre los que hay adultos, jóvenes y niños, hombres y mujeres, con respecto a la estatura, los tres restos mensurables alcanzan una media de 1157 metros de altura. En general son individuos de fuerte desarrollo muscular a consecuencia del ejercicio físico. Con respecto a las patologias, se ha detectado la existencia de hipoplasia dentaria que es un marcador de estrés ambiental, seguramente a consecuencia de haber estado sometidos a condiciones adversas, por desnutrición o por padecimiento de alguna enfermedad infecciosa.

No hay ajuares de objetos completos, salvo en un caso en que se colocó un pequeño cuenco carenado completo junto al parietal (Blasco, C. y otros, 1991: 58). En la mayoría de las ocasiones encontramos objetos fragmentados más o menos dispersos en la fosa, relativamente alejados de la inhumación, correspondiente a material amortizado mezclado con las tierras con las que se colmató la tumba. Conviene destacar también la aparición, en las cinco tumbas de Perales del Rio, de un fragmento de molino amortizado, una circunstancia que se repite en los cinco enterramientos exhumados en el Cerro del Obispo donde, segün sus excavadores "cada enterramiento poseía un molino y su mano, frecuentemente inutilizados rituaimente" (MENÉNDEZ, M. L., y otros, 1988: 102) Desconocemos si esta presencia de molinos, amortizados o no, se repite en La Loma del Lomo o en cualquier otro de los enterramientos exhumados pues, desgraciadamente, no se hace referencia a las características de las piedras recuperadas en las fosas de enterramiento. Otro aspecto es la posible relación que puedan tener los enterramientos con otras fosas próximas que contienen abundantes restos de huesos animales, como si se tratara de los desperdicios de un banquete 0 incluso de la acumulación reiterada de carne de consumo como ofrenda (BLASCO, M. ${ }^{a} \mathrm{C}$. y otros, 1991 68). En este sentido no puede descartarse que las "ofrendas" de animales completos localizadas en algunas fosas sin enterramientos, tanto en La Loma del Lomo como en Perales del Río puedan estar en relación con ajuares funerarios de alguna de las inhumaciones próximas (caso del perro depositado en una hoya próxima al enterramiento 9 de la Loma del Lomo) o incluso tengan otra explicación relacionada con el mundo de los muertos y se trate de auténticos cenotafios.

\section{LA ETAPA DE PLENITUD DEL HORIZONTE COGOTAS I}

Este momento se caracteriza, fundamentalmente por la utilización de nuevas técnicas decorativas en las cerámicas finas y la elaboración de diseños más complejos y barroquizantes en los que, junto a motivos geométricos restilíneos, se realizan también temas curvilíneos. Por otra parte, aunque la expansión de Cogotas hacia áreas periféricas 


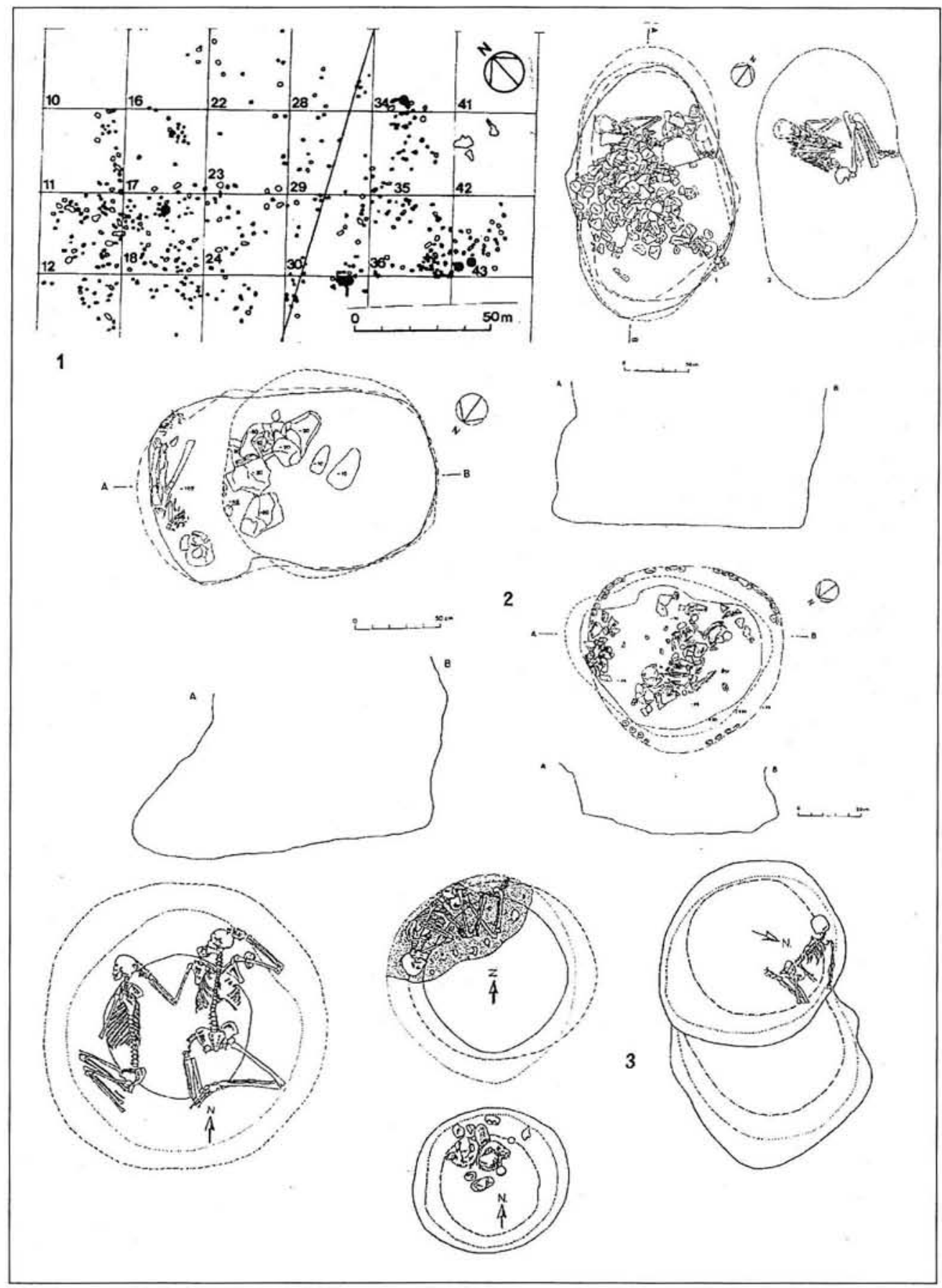

Figura 8.-8.1 y 8.2.-Plano y enterramientos del Caserio de Perales (Según Blasco y Otros, 1991). 8.3.-Enterramientos de La Dehesa (Según Macarro y Silva, 1996) 
se inicia desde la etapa de formación, parece evidente que es en esta fase de plenitud cuando asistimos al apogeo de su presencia en territorios periféricos donde las cerámicas decoradas que constituyen su seña de identidad aparecen en numerosas estaciones. Entre los yacimientos periféricos que incorporan las cerámicas Cogotas I podemos citar La Cuesta del Negro de Purullena, El Cerro de la Encina en Monachil, y Fuente Alamo, todos ellos en el sureste; El Llanete de Los Moros en Montoro, Cástulo y Ategua en el Alto y Medio Guadalquivir; Acinipo y Montemolín en otros puntos de Andalucia; la cueva de Boquique y Castillo de Alange en Extremadura; Solacueva y Moncin en el Valle del Eòro; Oropesa, Cabezo Redondo y El Tabayá en Levante. Una enumeración que no es más que la punta de un iceberg constituído por más de un centenar de yacimientos.

La evidencia de que la mayoría de las cerámicas Cogotas I localizadas fuera de su "área nuclear" son de origen local (BLASCO, M. ${ }^{a}$ C., ARRIBAS, J G., y MARTín DE LA CRUZ, J C., 1993), viene a reafirmar que la intensidad de los contactos llegó a ser mayor de lo que se creía en un principio ya que no son productos exóticos, fruto de un comercio más o menos activo, o de la presencia esporádica de gentes desplazadas hasta alli. sino más bien consecuencia de una estética y una técnica plenamente asumidas y dominadas que han pasado a formar parte de la cultura material y, en consecuencia, de la actividad industrial propia de estos grupos de la periferia, los cuales las incorporan a su producción, aunque todo parece indicar que estas piezas son sustituidas por otras inspiradas en nuevas corrientes, antes de que caigan en desuso en su area de origen (Cuencas de Duero y del Tajo).

En la zona nuclear los yacimienos conocidos, adscritos a esta etapa aumentan día a día, distribuídos muy desigualmente, en particular, en el Valle del Tajo donde el volumen de la región de Madrid contrasta con el gran vacio de la cuenca media que lentamente empieza a rellenarse. A lo largo de este período se han llegado a distinguir dos momentos: uno de plenitud y otro evolucionado o final, para los cuaies contamos con una serie de fechas, tanto en el Valle del Duero como en el del Tajo (véase Tabla 4 pá gina siguiente).

Al igual que en las tablas anteriores hemos omitido las dataciones de las cuevas del Asno y La Vaquera, por no estar muy clara su asociación con materiales Cogotas I, y la secuencia del Castillo de Burgos (CASTRO. P, MiCo, R., y SANHAuiA, E., 1995: 104), por presentar cierta dispersión, algo que, aunque con menos margen, también ocurre con las dataciones del nivel III de Atapuerca donde se recuperaron materiales Cogotas I.

Con estas salvedades, las dataciones se agrupan entre el 1260 y el 870 a. C., que en fechas calibradas se elevan hasta 1489-1035 a. C., unos valores muy proximos en ambas cuencas y que coinciden, como es lógico el Bronce Tardio y Bronce Final I del sureste, (Molina, F., 1977) momento en el que se inscriben los niveles que han proporcionado la mayor parte de los materiales Cogotas I de plenitud en esta área. Por otra parte, las etapas finales son las que conocen la llegada, al territorio nuclear de Cogotas I, de las fíbulas de codo de origen mediterráneo, fruto posiblemente de la incorporación de estos grupos a circuitos comerciales más amplios. 


\section{TABLA 4}

\begin{tabular}{|c|c|c|c|c|c|c|}
\hline Yacioriento & Laboratorto & bp & ane & cal e & \pm & Bibliografia \\
\hline \multicolumn{7}{|l|}{ CUENCA DEL DUERO } \\
\hline Los Tolmos & CSIC: 479 & 3180 & 1230 & 1466 & 50 & Castro, Lull y Mico. 1996 \\
\hline Los Tolmos & $\mathrm{CSIC} .407$ & 3010 & 1060 & 1295 & 50 & Castro, Lul! y Micó, 1996 \\
\hline Atapuerca, El Portalón & I. -9879 & 3170 & 1220 & 1455 & 130 & Castro, Lull y Micó, 1996 \\
\hline Atapuerca, El Portalón & I-9881 & 3340 & 1390 & & 160 & Castro. Lull y Micó. 1996 \\
\hline Atapuerca, El Portalon & $1-9880$ & 3420 & 1520 & & 190 & Castro, Luil y Mico, 1996 \\
\hline Atapuerca. El Portaion & CSIC-531 & $24 \overline{50}$ & 900 & 1017 & 50 & Castro, Lull y Mico, 1996 \\
\hline S. Román de la Homija & $\mathrm{I}-9604$ & 2960 & 1010 & 1192 & 95 & Castro. Lull y Mico, 1996 \\
\hline S. Román de la Hornija & I-9603 & 2820 & 870 & 1035 & 150 & Castro. Lull y Mico, 1996 \\
\hline Cueva de los Espinos & $\mathrm{I}-11116$ & & 880 & 1003 & 95 & Castro y otros, 1995 \\
\hline Cueva de los Espinos & I-11117 & & 1170 & 1398 & 95 & Castro y otros. 1995 \\
\hline Boecillo & CSiC-557 & 3170 & 1220 & 1460 & 60 & Castro, LuIl y Micó. 1996 \\
\hline Tapado de Caldeiza & $\mathrm{KN}-2770$ & 3210 & 1260 & 1489 & 55 & Castro. Lull y Micó, 1996 \\
\hline Tapado de Caldeira & CSIC-597 & 2990 & 1040 & 1228 & 50 & Castro. Luill y Micó. 1996 \\
\hline Tapado de Caldeira & $\mathrm{KN}-2769$ & 3290 & 1340 & 1578 & 55 & Castro. Lull y Micó. 1996 \\
\hline \multicolumn{7}{|l|}{ CUENCA DEL TAJO } \\
\hline Fabrica de Ladrillos & TL UAM & 3189 & 1198 & & 249 & Arribas y otros, 1989 \\
\hline Fabrica de Ladiillos & TL UAM & 3066 & 1078 & & 257 & Artibas y otros, 1989 \\
\hline Fabrica de Ladrillos & TL UAM & 2882 & 894 & & 213 & Arribas y otros. 1989 \\
\hline Fabnica de Ladrillos & I-13, 748 & 2840 & 890 & 1018 & 90 & Castro, Lull y Micó, 1996 \\
\hline Ecce Homo & CSIC-167 & 2990 & 1040 & 1243 & 70 & Castro, Lull y Micó, 1996 \\
\hline Ecce Homo & CSIC-164 & 3020 & 1070 & 1270 & 70 & Castro. LuIl y Micó, i996 \\
\hline Ecce Homo & CSIC- 163 & 3100 & 1150 & 1384 & 70 & Castro, Luil y Mico. 1996 \\
\hline Ecce Homo & CSIC- 165 & 3020 & 1070 & 1270 & 70 & Castro, Lull y Mico, 1996 \\
\hline
\end{tabular}

En la Cuenca del Duero el número de estaciones adscribibles a este horizonte se eleva a algo más de dos centenares, concentradas muy especialmente en la ribera del Duero y en las cuencas bajas de los afluentes más importantes, en territorios de especial rendimiento agropecuario. A pesar del número tan importante de estaciones conocidas, muy pocas han sido objeto de excavaciones en extensión por lo que la información disponible es muy fragmentaria. Únicamente sabemos que el hábitat característico sigue siendo el de los poblados de hoyos ubicados en lugares bajos y abiertos que pocas veces han conservado indicios de suelos e incluso huellas de postes que permitan identificar las plantas de las cabañas, aunque existen excepciones como la del Teso del Cuerno (Forfoleda, Salamanca), donde se ha identificado una estructura de planta rectangular y cabecera absidal con unos ejes de 9 por 4 metros. El perímetro está marcado por una 
alineación de agujeros de unos 15 a 20 centímetros de diámetro, separados entre sí 45 centimetros, en los que se encontraban embutidos los postes lígneos de sustentación de las paredes. En el interior queda la huella de otros cuatro postes centrales, de mayor envergadura, que debieron de servir de sustentación de la techumbre (MARTIN, J. I., y JMENEZ, M. C., 1988-89) (Figura 8.3).

Sin lugar a dudas el material más característico de este horizonte es la cerámica que ahora incorpora técnicas más variadas y una mayor complejidad y profusión ornamental. Entre las técnicas destacan el boquique, con un gran número de variantes, y la excisión, las cuales combinan entre sí y/o con la incisión, el puntillado y otras impresiones. Los temas siguen siendo geométricos, pero ahora a los motivos rectilíneos se suman guirnaldas curvilíneas. Además, en los momentos más tardíos, las bandas continuas se transforman en frisos metopados. Por otra parte, también en las fases más avanzadas, las decoraciones se enriquecen con la incrustación de materias colorantes, fundamentalmente blancos y rojos. Posiblemente por influencia de las primeras cerámicas pintadas postcocción bicromas que, junto a las incisas, también con incrustaciones de pigmentos, caracterizan el Bronce Final del sureste peninsular. Las morfologias presentan galbos muy marcados y pequenas bases planas, a veces claras imitaciones de prototipos metálicos. Entre los tipos nuevos hay que señalar las jarras y las grandes fuentes de marcados galbos (Figura 9.1).

Tanto la industria lítica como la ósea sufren un claro proceso de enrarecimiento. con la única excepción de los elementos de hoz, realizados sobre lascas cortas y espesas en forma de " $\mathrm{D}$ ", sin embargo la metalurgia (Figura 9.2 a 9.4) de estos momentos adquiere un especial interés, tanto por el número de hallazgos y la variedad tipológica de los mismos, como por los nuevos modelos que se generalizan, ya que, frente a las producciones del Bronce Antiguo, de clara influencia argárica, la metalurgia sincrónica al Horizonte Cogotas I es de clara procedencia atlántica como ya señalara Fernández Manzano, quien ha estudiado detalladamente los hallazgos metálicos del Bronce Final en Meseta Norte (FERNANDEZ MANZANO, J., 1986). En este trabajo se destaca no obstante, el escaso número de piezas contextualizadas en yacimientos Cogotas I, entre las que cabe mencionar varias fíbulas de codo, además de un puñal de empunadura bipartida relacionado con modelos centroeuropeos y dos brazaletes de morfologia relacionable con los galos tipo Bignam (FERNÁNDEZ MANZANO, J., 1986: 141-142), unos objetos que podrían haber llegado a la zona dentro de los mismos circuitos por los que circulan los productos procedentes de los talleres occidentales. Por el contrario son numerosos los hallazgos aislados integrados por piezas singulares y depósitos constituídos por un desigual número de objetos.

El mundo funerario mantiene las tradiciones anteriores de enterramientos en Fosas en el interior de los poblados, de lo que son buen ejemplo la triple inhumación de San Román de la Hornija, cuya fosa entregó un ejemplar de fibula de codo tipo Ria de Huelva (DeLIBES, G., 1978) (Figura 9.2) y el enterramiento de Renedo de Esgueva, ambos en la provincia de Valladolid, sin embargo, tal como se ha recogido en una pormenorizada sintesis (ESPARZA, A., 1990) los enterramientos asociados al Horizonte Co- 


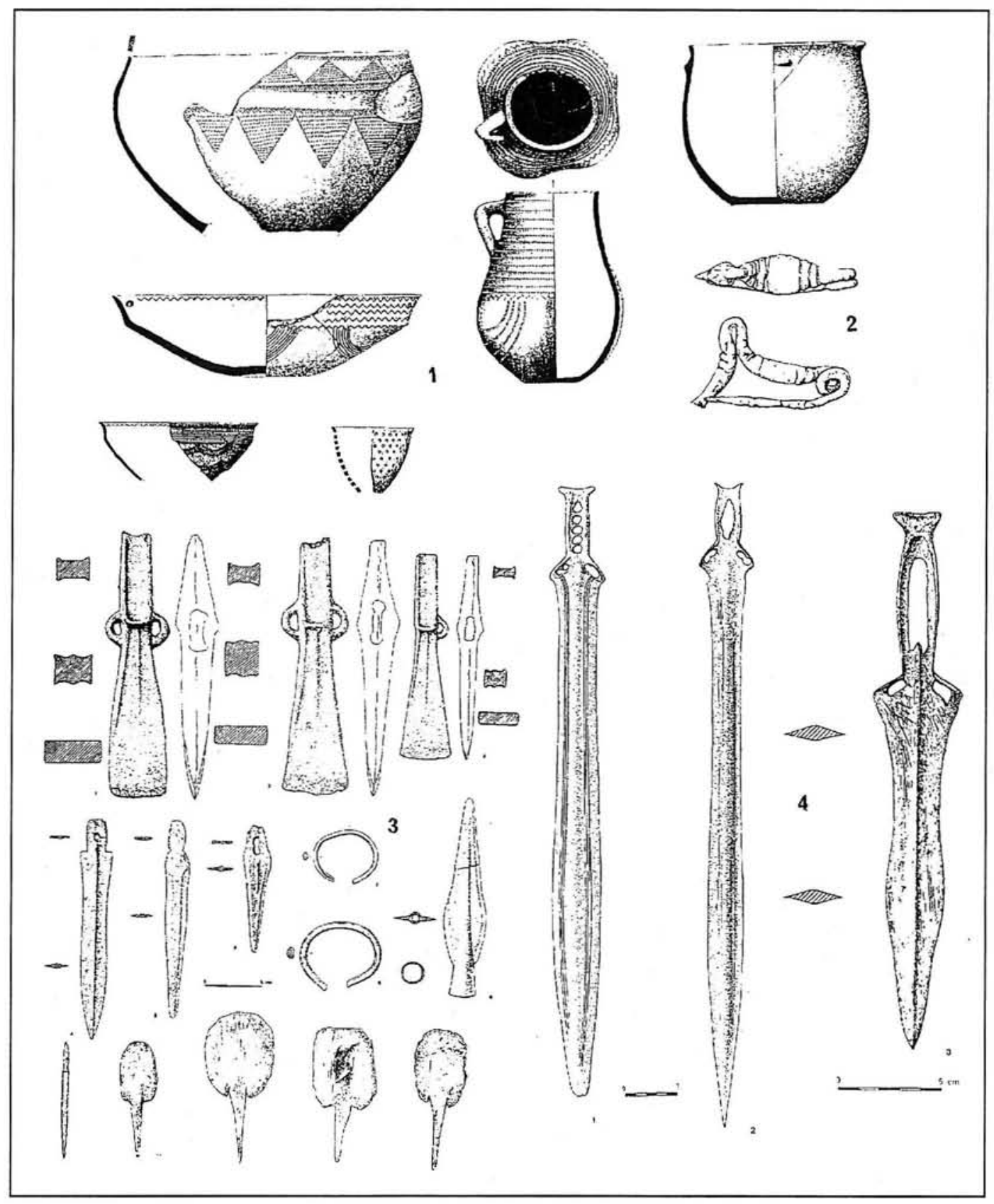

Figura 9.-Materiales cerámicos y metálicos del Horizonte Cogotas I de Plenitud en el Valle del Duero. 9.1.-Cerámicas del Teso del Cuerno (Según Martín y Jiménez,, 1988-89). 9.2, 9.3 y 9.4.-Fíbula de San Román de la Hornija, Depósito de Huerta de Arriba y espadas de lengua de carpa de Paredes de Nava y Frechilla (Según Fernández Manzano 1986) 
gotas I. corresponden sobre todo a restos depósitados en cuevas funerarias e, Incluso. en monumentos megalíticos, siendo relativamente frecuente la existencia de enterramientos secundarios y de depósitos de esqueletos incompletos (GoNZÁLEZ TABLAS, J , y FANO, A., 1994), un panorama que no dista demasiados de lo que encontramos en el Valle del Tajo (BLASCO, M. ${ }^{a}$ C., 1997).

En el Valle del Tajo nos encontramos con una situación muy similar a la del Duero. Si bien los yacimientos conocidos siguen concentrándose en la región de Madrid, aunque cada vez son más numerosos los hallazgos en el resto de la cuenca alta (Guadalajara) y Cuenca Media (Toledo). Todos los asentamientos conocidos responden al tipo "campos de hoyos", ubicados preferentemente en las terrazas bajas de los ríos aunque no faltan ejemplos situados en altura, como es el caso de Ecce Homo y la Muela de Alarilla. Mientras algunos establecimientos son de nueva fundación, otros, como el Caserío de Perales, La Dehesa o La Fábrica de Ladrillos de Preresa responden a instalaciones sobre lugares previamente ocupados y abandonados durante periodos más o menos prolongados. Más excepcional es el caso de Ecce Homo que, tras la ocupación Cogotas I se reocupará en distintos momentos de la Edad del Hierro.

Tanto las características de la cerámica como de la industria lítica (Figura 10. 3 y 10.4) son similares a las del Valle del Duero, sin embargo la metalurgia es más escasa y faltan los grandes depósitos de la Meseta Norte, a pesar de ello existen indicios de influencias de los talleres atlánticos, patentes, en algunos hallazgos descontextualizados, entre los que destacan algunas hachas de talón con rebordes y anilla lateral como las de Meco (Figura 10.1). (Monteagudo, L., 1965: 18) Sabiñán y Rueda (HeRnando, A., 1992, figuras 9.108 y 10,109), de tipología atlántica, aunque no puede olvidarse la aparición en el yacimiento alicantino de Mola d'Agrés. de un fragmento de molde para fundir este tipo de piezas (GIL MASCARELL. M., y TejeDO. M. E., 1992) Otra pieza que se ha atribuido al Bronce Final es la espada de Guadalajara (Figura 10.1) fechada entre el 1250 y el 1050 a.C. (Almagro Gorbea. M., 1972: 77) Pero sobre todo, hay que recordar el depósito de Sigüenza, constituido por dos espadas de lengua de carpa tipo Huelva (Figura 10.1) pertenecientes al Bronce Final III (COFFYN, A., 1985. pl. XXVII y p. 388) y tres pu" nales (HERNANDO, A., 1992, figura 17, $n{ }^{2} 188,189$ y 190), dos de ellos emparentados tipológicamente con los del depósito de Sansueña, un conjunto atribuido también al Bronce Final III (FERNANDEZ MANZANO, J., 1987: 105 y 106).

Entre las piezas bien contextualizadas hay que citar un punzón, en bronce, de sección cuadrada (Figura 4.3) recuperado en el arenero Soto (MARTinEZ NAVARRETE, M. ${ }^{a}$ I., y MÉnDEZ, A, 1983: 229-231) y la fíbula de codo (Figura 10.2) del arenero del kilómetro 8 '600 de la carretera de San Martín de la Vega, (BLASCO, M. ${ }^{2}$ C., 1987). En algunos de los "fondos" del Caserio de Perales, también con un contexto claramente Cogotas I de plenitud, se han obtenido varias piezas metálicas como punzones, varillas, un alfiler y una anilla de extremos apuntados y abiertos próxima a la metalurgia tipo Vénat (Figura 10.2). Especial interés tiene una de las varillas (Figura 10.2) que, por su tamaño y peso, puede ser un verdadero "lingote" del que se obtendría materia prima para la elaboración de pequeños objetos, si bien no se puede descartar tampoco que nos encontremos ante una 


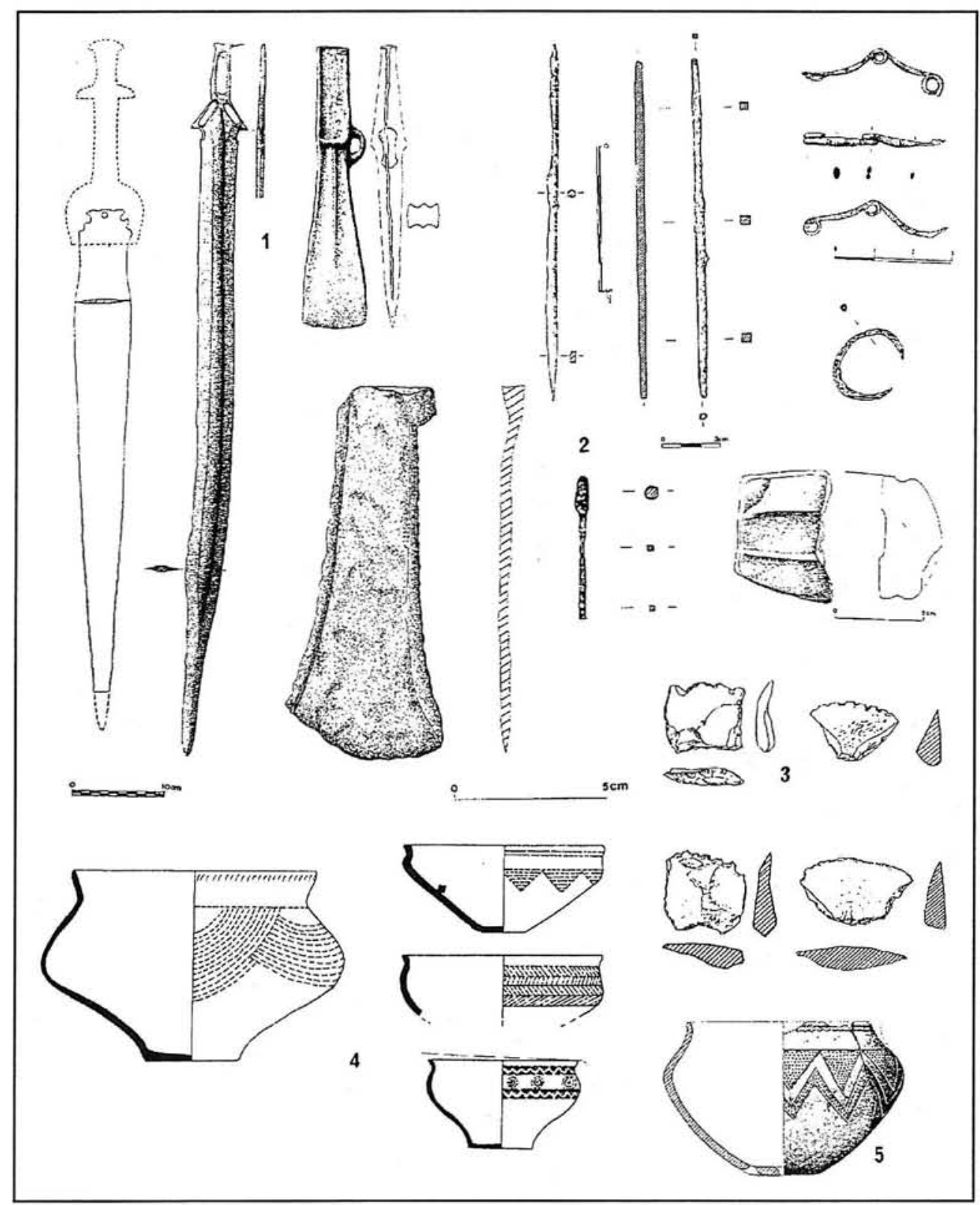

Figura 10.-Materiales metálicos y cerámicos del Horizonte Cogotas I de Plenitud en el Valle del Tajo.10.1.-Diversos objetos metálicos descontextualizados: Espadas de Guadalajara y Sigüenza y hacha de talón de Meco (Según Almagro, 1972; Coffyn, 1985 y Monteagudo, 1977, respectivamente) 10.2.-Diversas piezas aparecidas en contextos domésticos (Según Blasco y otros, 1995). 10.3.-Elementos de hoz del Arenero Soto (Según Martínez Navarrete y Méndez , 1983). 10.4.-Cerámicas de diversos yacimientos madrileños (según Fernández Posse, 1982).- 10.5.-Cerámica procedente de Olivares de La Fuente, Malpica (Toledo)

(Según Carrobles y otros 1994) 
verdadera varilla-moneda. Varios de estos objetos están realizados en bronce ternario, con un contenido desigual de plomo (BLASCO. M. ${ }^{a}$ C., y RoviRA, S., 1992-93: 411), una aleación excepcional entre los objetos metálicos asociados, hasta el momento, a contextos Cogotas I (FERNANDEZ MANZANO, J., 1986).

Un dato complementario es la aparición, en el yacimiento de La Fábrica de Ladrillos, de un lingote en forma de hacha plana obtenido en un molde monovalvo al que no se le ha limado la rebaba de los filos ni el muñón originado en la zona del vertido de la colada (Figura 10.2), la pieza tiene en la hoja un 59,44 de cobre y un 39,80 de plomo, mientras que en el talón la proporción es de un 34,72 de cobre y un 61,07 de plomo. No sabemos hasta qué punto la utilización del plomo en la elaboración de los bronces de los grupos Cogotas I es un hecho local o se trata de un fenómeno más generalizado. El mismo yacimiento, en el que ha aparecido este lingote, ha entregado también otros objetos metálicos, entre ellos un punzón biapuntado, una punta de flecha con pedúnculo y una punta de lanza con lengüeta para enmangue de hoja triangular.

La fabricación de objetos metálicos en el ámbito doméstico está testificada por un fragmento de molde de hacha plana recuperado en uno de los fondos del yacimiento del arenero del kilómetro $8^{\prime} 600$ de la carretera de San Martín de la Vega (Figura 10.2). También la presencia de lingotes plomados como las varillas o el hacha, antes citados, pueden ser indicio de cierto atesoramiento de mineral dentro de los poblados con el fin de abastecerse de materia prima para los trabajos metalúrgicos desarrollados dentro de estos ámbitos.

El mundo funerario repite los mismos esquemas que ofrece la Meseta Norte, advirtiéndose un cierto enrarecimiento de los enterrarnientos. Por otra parte, en yacimientos del Horizonte Cogotas I de plenitud, son numerosos los hallazgos de pequeñas porciones de restos óseos humanos dentro de las "fosas" de desechos domésticos, e incluso de algunos miembros en conexión anatómica aislados del resto del cuerpo como es el caso de la mano aparecida en uno de los fondos del yacimiento del kilómetro 7 de la carretera de San Martín de la Vega (MARTINEZ NAVARRETE, M. ${ }^{a}$ I., y A. MÉNDEZ, 1983), cuya interpretación resulta complicada. Un dato singular es la inhumación de un cuerpo descuartizado, colocado sobre un lecho de fragmentos cerámicos, dentro de una de las fosas del Caserio de Perales (BLASCO, M. ${ }^{2}$, y otros, 1991:62-63). Posiblemente en este panorama haya que incluir también algunas de las manifestaciones del yacimiento de la Dehesa (Alcalá de Henares, Madrid) donde se han recuperado enterramientos con cuerpos arrojados a las fosas e, incluso, cráneos aislados de sus cuerpos (Figura 8.3), aunque desconocemos los materiales a los que estaban asociadas estas manifestaciones.

Tanto en el Valle del Duero como en el del Tajo, el Horizonte Cogotas I se desvanece a inicios del siglo IX a.C., sin que, hasta el momento, existan yacimientos en los que pueda seguirse una transición progresiva, no obstante una de las fechas de C14 del yacimiento vallisoletano de Soto de Medinilla, recientemente publicada: $2710 \pm 100$ BP (ESCUDERO, Z., 1995: 214), podría ser un indico de la formación del Horizonte Soto en las postrimerías de Cogotas I. Por otra parte, la progresiva incorporación a las sintaxis compositivas de las cerámicas de frisos metopados y la utilización frecuente de incrustacio- 
nes de pigmentos podrian indicar también que los últimos grupos de Cogotas I conocen ya las nuevas modas y técnicas ornamentales que en esos momentos se están adoptando en los conjuntos vasculares del Bronce Final del sureste peninsular y que, en estas tierras del interior se generalizarán en momentos propios del Hierro Antiguo.

\section{BIBLIOGRAFIA}

Almagro BasCh. M. (1960). "Hallazgos arqueológicos de Villaverde" Memorias de los Museos arqueológicos, XV-XVIII. Madrid. 5-29.

ALMAGRO GORBEA, M. (1972): "La espada de Guadalajara y sus paralelos peninsulares" Trabajos de Prehistoria, 29. Madrid: 55-82.

ANDREs, M. ${ }^{a}$ T. (1997): "Neolítico y Calcolítico". Crónica del Aragón Antiguo. De la Prehistoria a la Alta Edad Media (1987-1993) I. Caesaraugusta 72. Zaragoza: 59-107.

ARRIBAS, J. G.: CALDERON, T., y BLASCO. C. (1989)' "Datación absoluta por Termoluminiscencia. Un ejemplo de aplicación arqueológica" Trabajos de Prehistoria, 46. 231- 246.

AuBET, M. ${ }^{\circ}$ E., SERNA, M. ${ }^{\circ}$ R.; ESCACENA, J L., y RuIZ DELGADO, M. M. ${ }^{a}$ (1983)' La Mesa de Setefilla. Lora del Rio (Sevilla). Campaña 1979. "Excavaciones arqueológicas en España, 122". Madrid.

AYALA, M. (1991). El poblamiento argárico en Lorca. Estado de la cuestión. Lorca.

Baibin, R., Valiente, J., y MUSSAT, M." T. (1995). Arqueología en Guadalajara. Junta de Comunidades de Castilla-La Mancha. Toledo.

BAQUEDANO. M. ${ }^{a}$ I., y BlanCO, F. (1994): "El Espinillo, un yacimiento importante de la. Edad del Bronce en Madrid". Revista de Arqueología. Año XV, ${ }^{\circ}{ }^{\circ} 155$, marzo. Madrid: $12-23$.

BLAS, M. A. de (11981): "Una alabarda procedente del Valle del Manzanares (Madrid)". Zephyrus, $X X X I I-X X X I I I$. . 157-166.

BíASCO, M. ${ }^{2}$ C. (1987): "Un ejemplar de fíbula "ad ochio" en el Valle del Manzanares", Boletín de la Asociación española de amigos de la Arqueologia, $n .{ }^{\circ} 23$. Madrid: 1828.

BLASCO, C. (ed.) (1994): El horizonte campaniforme de la región de Madrid en el centenario de Ciempozuelos. Dep. de Prehistoria y Arqueologia, UAM, Madrid.

- (1997): "Manifestaciones funerarias de la Edad del Bronce en la Meseta" Saguntum, (PLAV). 30. 173-190.

Blasco, C.: ARRIBAS, J., y MARTIN DE la CRUZ, J. C. (1993). "Mineralogical and textural analysis of Late Bronze Age sherds" European Ceramic Society third Conference. Madrid: 520- 525.

BLASCO. M. ${ }^{a}$ C.: BAENA, J., y LiESAU, C. (1998): La Prehistoria madrileña en el gabinete de antigüedades de La Real Academia de la Historia. Los yacimientos Cuesta de la 
Reina (Ciempozuelos) y Valdocarros (Arganda del Rey). Dep. de Prehistoria y Arqueología, UAM, Madrid.

BlasCo, M. ${ }^{a}$ C.; CAlle. J. y SÁnCHEZ-CAPIlla, M. ${ }^{2}$ L. (1995) "Fecha de C14 de la Fase Protocogotas I del yacimiento del Caserio de Perales del Rio. Cuadernos de Prehistoria y Arqueología de la Universidad Autónoma de Madrid, 22. Madrid: 83-90.

- (1995) "Contribución al conocimiento de la metalurgia de la Edad del Bronce en el Alto Tajo y su marco cultural" Extremadura Arqueológica V. Cáceres: 115-128.

BlasCo, M. ${ }^{a}$ C.; CALle, J., SÁNChEZ-CAPilla, M. ${ }^{a}$ L., ROBleS, F. J.; GONZÁlEZ, V., y GONZA. LEZ, A. (1991): "Enterramientos del Horizonte Protocogotas en el valle del Manzanares". Cuadernos de Prehistoria y Arqueología de la Universidad Autónoma de Madrid, 18. Madrid: 55-112.

BlasCo, M. ${ }^{a}$ C., y ROViRA, S. (1992-93). "La metalurgia del cobre y del bronce en la región de Madrid". Tabona, VIII-II. Universidad de La Laguna: 397-415.

Bueno, P. Jimênez, P., y BARRoso, R. (1995). "Prehistoria Reciente del nordeste de Guadalajara". En Arqueología de Guadalajara., Toledo: 71-95.

CABallero, J.; Porres, F., y SalazAr, A.(1993). "El campo de fosas de "El Cogote" (La Torre, Avila)". Numantia, 4, Valladolid. 93-110.

CARRobles, J., MuÑOZ, K., y Rodrfguez. S. (1994): "Poblamiento durante la Edad del Bronce en la Cuenca media del río Tajo" Actas del Simposio: La Edad del Bronce en Castilla-La Mancha. Diputación de Toledo: 173-200.

CASTLLO, A. del (1928). La cultura del vaso campaniforme. Barcelona.

CASTro, P., LUll, V., y MiCo, R. (1996): Cronología de la Prehistoria reciente de la Península Ibérica y Baleares (c. 2800.900 cal ANE). BAR International Series 652, Oxford

CASTRO, P. Mico, R., y SANAHUjA, E. (1995): "Genealogía y cronología de la "Cultura de Cogotas I". Boletín del Seminario de Arte y Arqueologia, LXI, Valladolid: 51-118.

COFFYN, A. (1985): Le Bronze Final atlantiquie dans la Peninsule lberique. París.

CONTRERAS, F. (1995). "Peñalosa. Un proyecto de investigación de la Edad del Bronce en el Alto Guadalquivir". Trabalhos de Antropologia e Etnología, vol. 35 (1). Porto: 143-157.

CuNLIFFE, B. (1992): "Pits. preconceptions and propitiation in the British Iron Age". Oxford Journal of Archaeology, vol. $11, n .^{\circ} 1$, marzo. Oxford: $69-83$.

DELIBES, G. (1971): "Una necrópolis de inhumación individual de la Edad del Bronce en Villalmanzo (Burgos)". BSAA, XXXVII. Valladolid, pp. 407-416.

- (1977) El Vaso campaniforme en la Meseta norte española. Valladolid.

- (1978). "Una inhumación triple de la facies Cogotas I en San Román de la Hornija (Valladolid). Trabajos de Prehistoria, vol. 35. Madrid pp. 225-250.

- (1993): "Sal y jefaturas: una reflexión sobre el yacimiento del Bronce Antiguo de Santioste, en Villafáfila (Zamora)". Brigecio, 3. Benavente: 33-46. 
- (1995a). "Neolitico y La Edad del Bronce" en Historia de Zamora. De los orígenes al Medievo. Zamora: 49-100.

- (1995b): "Avila, del Neolítico al Bronce" en Historia de Avila. I Prehistoria e Historia Antigua. Avila: 23-102.

Delibes, G., y ESPARZA, A. (1985) "Neolítico y Edad del Bronce" en Historia de Burgos (Tomo I. Edad Antigua) Burgos: 117-177.

DeliBes, G., y Fernandez Manzano, J. (1981) "El Castro Proto- histórico de "La Plaza" en Cogeces del Monte (Valladolid) BSAA XLVII. Valladolid: 65 y ss.

DeLiBES, G., y otros (1985)' La Prehistoria del Valle del Duero. Tomo I de Historia de Castilla-León. Valladolid.

DIAZ-ANDREU, M. (1994a): La Edad del Bronce en la provincia de Cuenca. Cuenca.

- (1994b) "La Edad del Bronce en el Noroeste de la Meseta sur". Actas del Simposio "La Edad del Bronce en Castilla-La Mancha". Diputación de Toledo: 145-172.

ESCUDERO, Z. (1995): "Nuevos estudios sobre el poblado vacceo de "El Soto de Medinilla" (Valladolid)". En DeliBEs, G., y otros: Arqueología y Medio Ambiente. Valladolid: 179-218.

ESPARZA, A. (1990). "Sobre el ritual funerario de Cogotas I" Boletín del Seminario de Arte y Arqueologia. LVI. Valladolid: 106-143.

FABIÁN. J. F. (1993): "La secuencia cultural durante la Prehistoria reciente en el sur de la Meseta Norte española" $1 .^{\circ}$ Congreso de Arqueología Peninsular. Actas I. Trabalhos de Antropologia e Etnologia, vol. 33 (1-2). Porto: 145-178.

- (1995) El aspecto funerario durante el Calcolítico y los inicios de la Edad del Bronce en la Meseta Norte. Salamanca

Fernández Manzano, J. (1985). "La Edad del Bronce" Cap. IV en Delibes, G., y otros: 54-81.

- (1986): Bronce Final en la Meseta Norte española. El utillaje metálico. Aimazán.

FERNÁNDEZ POSSE, M. ${ }^{a}$ D. (1982) "Consideraciones sobre la técnica de boquique". Trabajos de Prehistoria, 39., Madrid: 45-84.

FERNANDEZ POSSE, M. ${ }^{2}$ D.; GILMAN, A. y MARTIN, C. (1996). Consideraciones cronológicas sobre la Edad del Bronce en La Mancha" Homenaje al Profesor Manuel Fernández-Miranda. II. Complutum extra 6.II. 111-138.

FERNANDEZ VEGA, A. (1980): "Canteras de Zarzaiejo (Madrid)". N.A.H. 10. Madrid: 41-64.

GAIBAR, C. (1974): "Descubrimiento de la terraza würmiense en la margen izquierda del río Manzanares: aportaciones paleoclimáticas. Nuevos restos y nuevos testimonios del madrileño hombre prehistórico y protohistórico". Estudios geológicos, XXX: 235-252.

GAiAn, C., y FernANDEZ VeGA. A. (1983) "Excavaciones en Los Dornajos (La Hinojosa,

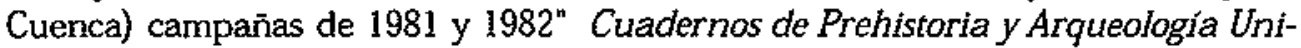
versidad Autónoma de Madrid 9-10. 31-49. 
GEANiNi, A. (1991) "Enterramiento de la Edad del Bronce en la Presa del Rey" ArqueoIogia, Paleontologia y Etnografia, 1. Comunidad de Madrid: 13-30.

GIL, J I.; MENENDEZ, M. L.; REYES, F., y REYES, J. L.(1988) "Excavaciones en el yacimiento del Bronce Medio del Cerro del Obispo, Castillo de Bayuela, Toledo" Actas del 1 Congreso de Historia de Castilla-La Mancha, tomo III. Junta de Comunidades de Castilia-La Mancha: 93-100.

Gil MASCAREli, M., y ENRIQUe TeJido, M. (1992): "Metalurgia del Bronce Final-Hierro antiguo del yacimiento de la Mola d'Agrés (Agrés Alicante)". Estudios de Arqueología ibérica y romana. Homenaje a Enrique Pla Ballester. Valencia. 39-50.

GonZALEZ TABLAS, J. (1984-85) "Proto-Cogotas I o el Bronce Medio de la Meseta: La Gravera de "Puente Viejo" (Avila)". Zephyrus XXXVII-XXXVIII. Salamanca: 267-276.

GONZÁleZ TABlaS, F. J., y FANO, M. A. (1994) ' El fenómeno de la muerte Cogotas I. una propuesta metodológica". Zephyrus, XLVII. Salamanca: 93-103

GONZÁLEZ TABLAS, J., y LARREN, H. (1990): "Un yacimiento del Bronce Medio en Zorita de los Molinos (Mingorria, Avila)". Cuadernos abulenses, 6. Avila: 61-80.

HARRISON, R. (1977) The Bell Beaker culture of Spain and Portugal. Cambridge Massachusetts.

HERNANDEZ, M. (1983) "La metalurgia prehistórica en el Valle medio del Vinalopó".Lucentum, II, pp. 17.42.

Hernando, A. (1992): Materiales metálicos de la Edad del Bronce en la Meseta. Armas. "Cuadernos de la Uned", Madrid.

HURTADO, V. (1987): "El megalitismo en el suroeste peninsular: Problemática en la periodización regional" en El megalitismo en la Península lbérica. Madrid. 31-44.

Jimeno, A. (1982): "Las fechas de C.14 del yacimiento de Los Tolmos de Caracena (Soria)" Trabajos de Prehistoria, 39. Madrid: 335-341.

- (1984): Los Tolmos de Caracena (Soria). EAE, 134, Madrid.

JIMENo, A., y FERnÁndeZ MORENo, J. J. (1991) Los Tolmos de Caracena (Soria). Campañas de 1981 y 1982) Aportación al Bronce Medio de la Meseta. Excavaciones Arqueológicas en España, 161. Madrid.

- (1992.a). "La metalurgia de la Edad del Bronce en la provincia de Soria: el contexto cultural ". Actas del $2 .{ }^{\circ}$ Symposium de Arqueologia soriana. Soria: 233-246.

- (1992,b): "El poblamiento desde el Neolítico a la Edad del Bronce: Constantes y cambios". Actas del 2. "Symposium de Arqueologia soriana. Soria: 69-101

Lull, V. (1983): La "cultura" de El Argar. Un modelo para el estudio de las formaciones económico-sociales prehistóricas. Madrid.

MaCarro, J. A., y SilVA, J. F. (1996): "Los enterramientos de "La Dehesa" (Alcalá de Henares); Aportaciones a los ritos funerarios de la Edad del Bronce en La Meseta". Reunión de Arqueología madrileña, Madrid: 123-126. 
MARTIN, J. I., y JIMÉNEZ, M. C. (1988-89): "En torno a una estructura constructiva en un "campo de hoyos" de la Edad del Bronce de la Meseta española (Fofoleda, Salamanca)" Zephyrus, XLI-XLII. Salamanca: 263-281

Martín, M. A., Misiego, J C., Pérez, F. J : Fernández, J. M., Sanz, F. J., y Marcos, G.(1993) "Documento funerario del Bronce Medio en la Submeseta norte: "Carrelasvegas" (Santillana de Campos, Palencia)". Boletin del Seminario de Arte y Arqueologia. $L I X$ Universidad de Valladolid: 69-83.

MARTIN VALLS, R., y DELIBES, G. (1989) La cultura del vaso campaniforme en las campiñas meridionales del Duero, El enterramiento de Fuente Olmedo (Valladolid) Va* lladolid.

MARTINEZ NAVARRETE, M. ${ }^{3}$ I. y M MÉNDEZ, A. (1983). "Arenero de Soto". Yacimiento de fondos de cabaña del Horizonte Cogotas I. Estudios de Prehistoria y Arqueología madrileñas. Madrid: 183-254.

MENÉNDEZ, M. L., Gil, J. I. REYES, F, y REYES, J. L. (1988) "Tipología del material procedente de la necrópolis del Bronce Medio del Cerro del Obispo. Castillo de Bayuela, Toledo" Actas del $1 .^{\circ}$ Congreso de Historia de Castilla-La Mancha, tomo III. Junta de Comunidades de Castilla La Mancha: 101-111.

Misiego, C. C., PÉrez, F. J., SANZ, F J., Marcos, G. J., y MarTín, M. A. (1992): "La Huelga. Bronce Medio en la Meseta Norte". Revista de Arqueologia, año XIII, n. ${ }^{\circ} 36$, agosto. Madrid: 18-25.

Molina, F (1977)- La cultura del Bronce Final en el sudeste de la Península Ibérica. Tesis doctorales de la Univ de Granada. 178.

MOlinA, F. y PAREJA, E. (1979) Excavaciones en la Cuesta del Negro (Purullena, Granada). Campaña de 1971. Excavaciones Arqueológicas en España. 86. Madrid.

MONTEAGUDO, L. (1965): "Hachas prehistóricas de Europa occidental". Coimbriga IV 18.

- (1977): Die Beile auf der Iberischan Halbinsel. Präehistorische Bronzefunde IX,6.

NÁJERA, T. (1984): La edad del Bronce en La Mancha occidental. "Tesis doctorales de la Universidad de Granada, n. ${ }^{\circ} 458 "$.

PAlomino, A. L., y RODRIGuez MARCOS, J A. (1994). "El yacimiento arqueológico de "Las Empedradas": un enclave del Bronce Medio en la Ribera del Duero burgalesa" NLmantia, 5: 59-72.

Pérez de BarRadas. J. (1926) "El Neolítico de la provincia de Madrid" Revista de Bibliotecas, Archivos y Museos del Ayuntamiento de Madrid, vol.III: 75-87.

- (1933-35) "Nuevos estudios sobre Prehistoria madrileña I. La "Colección Bento" Archivo de Prehistoria madrileña, IV-V-VI: 1-90.

- (1936). "Nuevos estudios de Prehistoria madrileña I. La Colección Bento". Archivo de Prehistoria madrileña, N-V-VI, 1933-35. Madrid: 1-90. 
PÉREZ Rodriguez, J. F. y Fernández Gimenez, J. M.a (1993): "Sobre la cocción de cerámica durante la Edad del Bronce. El yacimiento de "La Venta" (Alar del Rey, Palencia)". Numantia, 4, Valladolid: 27-40.

Perez Rodrfglez, J. F; Misiego, J. C., SAnZ, F J , Marcos, G., Martín, M. A., y Fernández GIMÉNEZ, J. M. a (1994) "La Huelga". Un interesante yacimiento de La Edad del Bronce en el centro de la Cuenca del Duero" Numantia, 5. Valladolid: 11-32.

POYATO, C. (1984-85): "Observaciones en torno a la cronología de la cerámica campaniforme, obtenida mediante C.14, en algunos yacimientos peninsulares" Cuadernos de Prehistoria y Arqueología de la Universidad Autónoma de Madrid. 11-12, Vol. I., Madrid: 93-106.

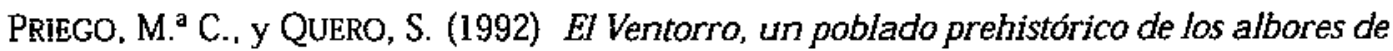
la metalurgia. "Estudios de Prehistoria y Arqueología madrileñas. 8. Madrid.

QuERo, S. (1982) "El poblado del Bronce Medio de Tejar del Sastre (Madrid)" Estudios de Prehistoria y Arqueología madrileñas: 183-247.

Rodriguez MarCoS, J. A. (1993) "El Carrizal" (Cogeces del Monte, Valladolid) un nuevo yacimiento de facies Proto/Cogotas I" Numantia, 4. Valiadolid: 61-74.

RODRígUEZ, J. A., y ABARQUERO, J. (1994): "Intervención arqueológica en el yacimiento de la Edad del Bronce de "El Cementerio", Quintanilla de Onésimo (Valladolid)" Numantia, 5. Valladolid: 33-58.

ROVIRA, S. (1989): "Recientes aportaciones para el conocimiento de la metalurgia primitiva en la provincia de Madrid: Un yacimiento campaniforme en Perales del Río (Getafe, Madrid)" Actas del XIX Congreso Nacional de Arqueologia, Vol. I. Zaragoza: 355-367.

ROVIRA. S.: MONTERO, I., y CONSUeGRA, S. (1989) "La metalurgia de la Edad del Bronce en la provincia de Soria: Estudio analitico" Actas del $2^{\circ}$ Symposium de Arqueologia soriana. Vol I. Soria: 247-260.

SESMA, J. (1993) ' "Aproximación al problema del hábitat campaniforme: El caso de Las Bardenas Reales de Navarra". Cuadernos de Arqueología de la Universidad de Navarra, 1. Pamplona: 53- 119.

UlREICH, H.; Negrete, M. ${ }^{a}$ A., y PUCH, E. (1994) "Cerámica decorada de Hoyas del Castillo (Pajaroncillo, Cuenca), Corte 4" BSAA, LX: 105-137.

VALIENTE, J. (1987): Loma del Lomo (Cogolludo, Guadalajara). Excavaciones arqueológicas en España, 152. Madrid.

- (1990-91) "Sobre enterramientos infantiles de la Edad del Bronce" Cuadernos de Prehistoria y Arqueologia castellonenes n. ${ }^{\circ} 15:$ 143-155.

- (1992a). La Loma del Lomo II. Cogolludo (Guadalajara) Guadalajara.

- (1992b: "Notas de metalurgia prehistórica en Guadalajara" Wad-al-Hayara, 19.: 39-49.

- (1993) "Un rito de fertilidad agraria de la Edad del Bronce en la Loma del Lomo (Cogolludo, Guadalajara)" Homenaje a José M. ${ }^{3}$ Blázquez I. Madrid: 253-265. 
- (1995): "El hábitat eneolítico de La Loma del Lomo (Cogolludo, Guadalajara)" En Balbin, Valiente y Mussat (coord). Arqueologia en Guadalajara Toledo: 137-149.

VINEE, A., y otros (1991) "Nuevos datos acerca del yacimiento de Santioste, Otero de Sariegos" Anuario 1991 Inst. de Estudios Zamoranos Florián Ocampo, Zamora, pp. 175-191.

VV.AA. (1987) 130 años de Arqueología de madrileña. Comunidad de Madrid. 